\title{
MATHEMATICAL MODELING OF DIESEL ENGINE OPERATION MODE INFLUENCE ON MASS EMISSION OF PARTICULATE MATTER WITH EXHAUST GASES USING MICROTUNNEL
}

\author{
Andrey Polivyanchuk ${ }^{1}$ \\ Igor Gritsuk ${ }^{2}$ \\ Elena Skuridina ${ }^{3}$
}

DOI: https://doi.org/10.30525/978-9934-588-53-2-56

\begin{abstract}
The work is devoted to solving an urgent scientific and practical task: establishing mathematical models that describe the effect of operating modes of diesel engines on the content in the exhaust gases of a dangerous pollutant - particulate matter (PM). The purpose of the work has been to create and study the accuracy and practical suitability of the calculation method estimating concentrations and emissions with exhaust gases PM by means of mathematical modeling of the influence on them of parameters that determine steady-state and unsteady diesel operation modes. The following research methods have been used in the work, such as: analysis and synthesis of information, mathematical modeling, experimental studies, and computational experiment. The studies have been carried out on the basis of the motor stand of a $4 \mathrm{ChN12/14}$ autotractor diesel equipped with a partial-flow system for diluting EG with air - MKT-2 microtunnels. Measurements of mass and volume concentrations $-\mathrm{c}_{\mathrm{pt}}(\mathrm{g} / \mathrm{kg})$ and $\mathrm{C}_{\mathrm{pt}}\left(\mathrm{g} / \mathrm{mn}^{3}\right)$, mass $-\mathrm{PT}_{\text {mass }}(\mathrm{g} / \mathrm{h})$ and specific $-\mathrm{PT}_{\mathrm{p}}(\mathrm{g} / \mathrm{kWh}) \mathrm{PM}$ emissions have been carried out by the gravimetric method with errors of \pm 3 .. 10\% in accordance with the requirements of regulatory documents - ISO8178 standard, UNECE Rules R-49, R-96, etc. The parameters, which determine the mode of operation of the diesel engine, have been considered: during the studyof

\footnotetext{
${ }^{1}$ Doctor of Technical Sciences, Professor,

Department of Urban Environmental Engineering,

O.M. Beketov National University of Urban Economy in Kharkiv, Ukraine

${ }^{2}$ Doctor of Technical Sciences, Professor,

Department of Operation of Ship Energy Systems,

Kherson State Maritime Academy, Ukraine

${ }^{3}$ Graduate Student, Department of Urban Environmental Engineering,

O.M. Beketov National University of Urban Economy in Kharkiv, Ukraine

(C) Andrey Polivyanchuk, Igor Gritsuk, Elena Skuridina
} 
the steady-state modes - the number of revolutions of the engine crankshaft $\left(\mathrm{n}, \mathrm{min}^{-1}\right)$ and the load (L,\%); in the study of unsteady modes - the parameters $\mathrm{n}$ and $\mathrm{L}$ and the rate of change over time $-\Delta \mathrm{n} / \Delta \mathrm{t}$ and $\Delta \mathrm{L} / \Delta \mathrm{t}$. As a result of studying concentrations and emissions PM at steady operation modes, the type has been selected and the most reliable regression dependence has been established - a second-order polynomial model that allows us to estimate the values of $\mathrm{C}_{\mathrm{pt}}, \mathrm{PT}_{\text {mass }}$ and $\mathrm{PT}_{\mathrm{p}}$ in the ranges of variation of the parameters $\mathrm{n}$ and $\mathrm{L}-1000 \ldots 2000 \mathrm{~min}^{-1}$ and $25 \ldots 100 \%$. The RSM of the established dependencies when determining the indicated values is comparable with the errors of microtunnels MKT-2 and is $\pm 0.0042 \mathrm{~g} / \mathrm{mn}^{3}$, $\pm 2.02 \mathrm{~g} / \mathrm{h}, \pm 0.077 \mathrm{~g} / \mathrm{kWh}$. A dependence for indirectly determining the mass concentration of PM in the exhaust gases at unsteady diesel operating modes, which are characterized by a duration of $10 \ldots 30 \mathrm{~s}$ and ranges of variation of the parameters $\mathrm{n}, \mathrm{L}, \Delta \mathrm{n} / \Delta \mathrm{t}$ and $\Delta \mathrm{L} / \Delta \mathrm{t}$, given in dimensionless form: $0.4 \ldots 0.8,0.3 \ldots 1.0,-0.2 \ldots 0.2$ and $-0.35 \ldots 0.35$, respectively, has been established. The deviation of the calculated and experimental data when using this dependence is $\pm 0.005 \ldots 0.006 \mathrm{~g} / \mathrm{kg}$, which is comparable with the sensitivity limit of MKT-2. A satisfactory accuracy and practical suitability of the indirect optical-gravimetric method for controlling PM concentrations and emissions at steady-state diesel engine operating modes were proposed and experimentally confirmed.

\section{Introduction}

Among the most dangerous pollutants that enter the atmosphere with exhaust gases (EG) of diesels and significantly degrade air quality indicators, there are solid particles (PM) [1]. The averaged mass emission of this substance from EG, which is determined taking into account the operating conditions of the engine, is one of the main normalized environmental indicators of a diesel engine [2]. At the same time, for PM take all the material, assembled on a special filter with fluorocarbon coating after passing through it a EG diesel, diluted with clean air to a temperature not exceeding $52^{\circ} \mathrm{C}$ is the dew point of the liquid hydrocarbons that make up the PM.

The methodology for determining PM mass emissions is regulated by regulatory documents and involves the use of the gravimetric measurement method, which is characterized by an increased cost, laborious- 
ness and duration of the test procedure [3]. To implement this method, special expensive equipment is required: a dilution tunnel, in which the natural process of PM penetration into the atmosphere by mixing the EG of the diesel engine with air is simulated and PM samples are collected on filters to further determine the concentration and emissions of PM from the EG [4]. In this regard, when conducting environmental diagnostics of diesel engines according to exhaust gas toxicity indicators, the urgent task is to create more economical, easy-to-use, and highspeed indirect methods for controlling PM content in EG $[5 ; 6]$. One of these methods is a computational research method based on the use of mathematical models of the influence of diesel operating modes on PM concentrations and emissions $[7 ; 8]$.

The purpose of the work has been to create and study the accuracy of the calculation method for estimating PM content in diesel EG by mathematical modeling of the influence of parameters that determine stable and unstable engine operation modes on concentrations, mass and specific emissions of PM. To achieve this goal, the following tasks have been solved:

1) development of an experimental setup for the study of PM content in exhaust gases on the basis of a motor diesel stand equipped with a gravimetric monitoring system $\mathrm{PM}$ - microtunnel;

2) mathematical modeling of the influence of parameters that determine the stable modes of diesel operation on the concentration and mass emissions of PM;

3) mathematical modeling of the influence of parameters that determine the unstable modes of diesel operation on PM concentration;

4) creation and research of an indirect optical-gravimetric method for controlling PM concentrations and emissions at steady-state diesel operation modes.

Below are the results of solving these problems.

\section{Experimental installation for studying the content of PM in EG}

The experimental setup was assembled on the basis of the motor stand of a 4ChN12/14 autotractor diesel engine, equipped with control means and control devices for parameters characterizing stable and unstable engine operation modes, as well as an automated gravimetric control system for PM - microtunnels MKT-2 (Figure 1). 


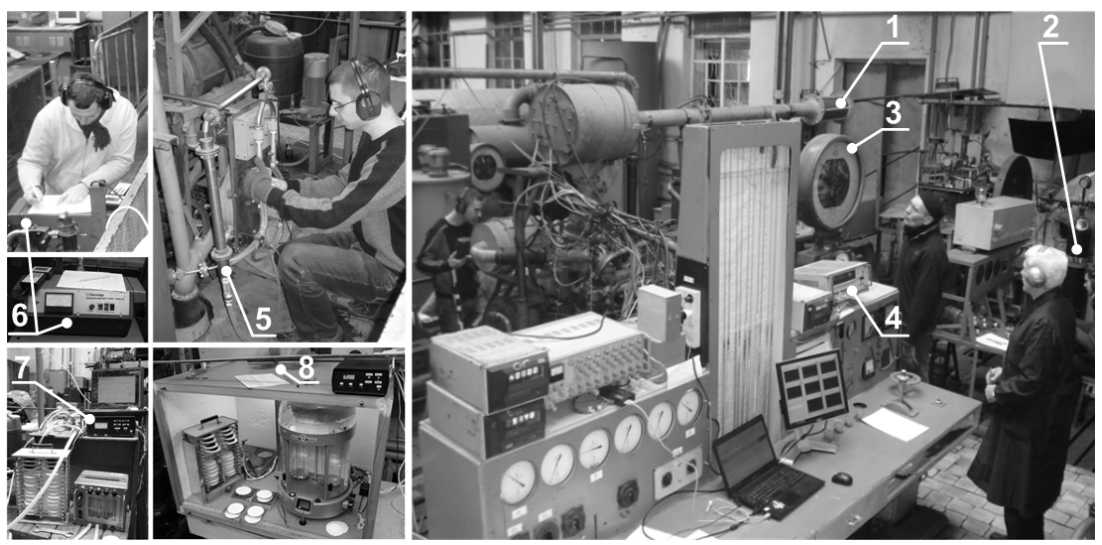

Figure 1. General view of the motor diesel engine stand 4ChN12 / 14 with microtunnels MKT-2:

1 - mass air flow meter; 2 - fuel mass flow meter; 3 -torque meter; 4 -a measure of the number of revolutions of the engine crankshaft; 5 - gravimetric control system PM - microtunnels MKT-2; 6 - exhaust smoke meter; 7 - electronic control module

MKT-2, 8 - camera for stabilization and weigh-ing of filters

\section{Basic elements, operating principle and technical characteristics of MKT-2}

Microtunnel MKT-2 [9] is a compact partial-stream system for diluting EG of a diesel engine with air, sampling and analysis of PM samples, designed in accordance with the requirements of international regulatory documents: ISO8178 standard, UNECE Rules R-49, R-96, etc. The structure of MKT -2 includes the following main elements (Figure 2, 3):

1) a sampling system designed to dilute the share of EG - 0,02 .. 1,2\% by air in a ratio of 1: $4 \ldots 1: 30$; it contains three subsystems:

a) a system for selecting a fraction of the exhaust gas stream, which includes:

- a sampler, which is a stainless steel pipeline with an inner diameter of $6 \mathrm{~mm}$ and a length of $80 \mathrm{~mm}$, mounted on the axial line of the exhaust pipe of the diesel towards the flow of the EG;

- transportation pipeline of sample (PS) with an inner diameter of $6 \mathrm{~mm}$ and a length of $80 \mathrm{~mm}$;

- regulator expense EG by throttling the transverse cross-section PS; 
Chapter «Engineering sciences»

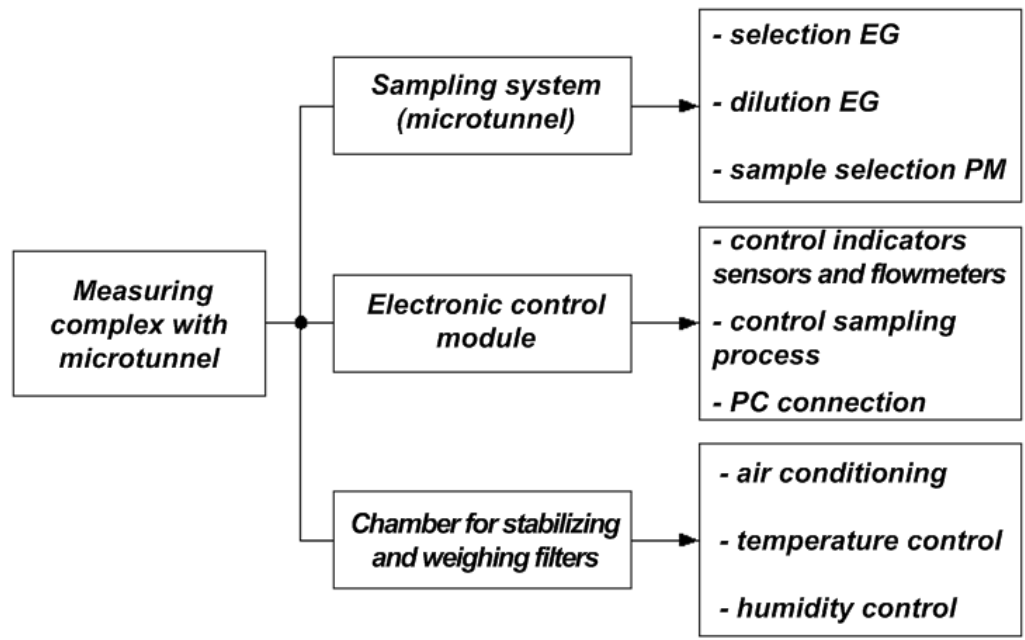

Figure 2. The main elements of MKT-2 and the functions that they perform
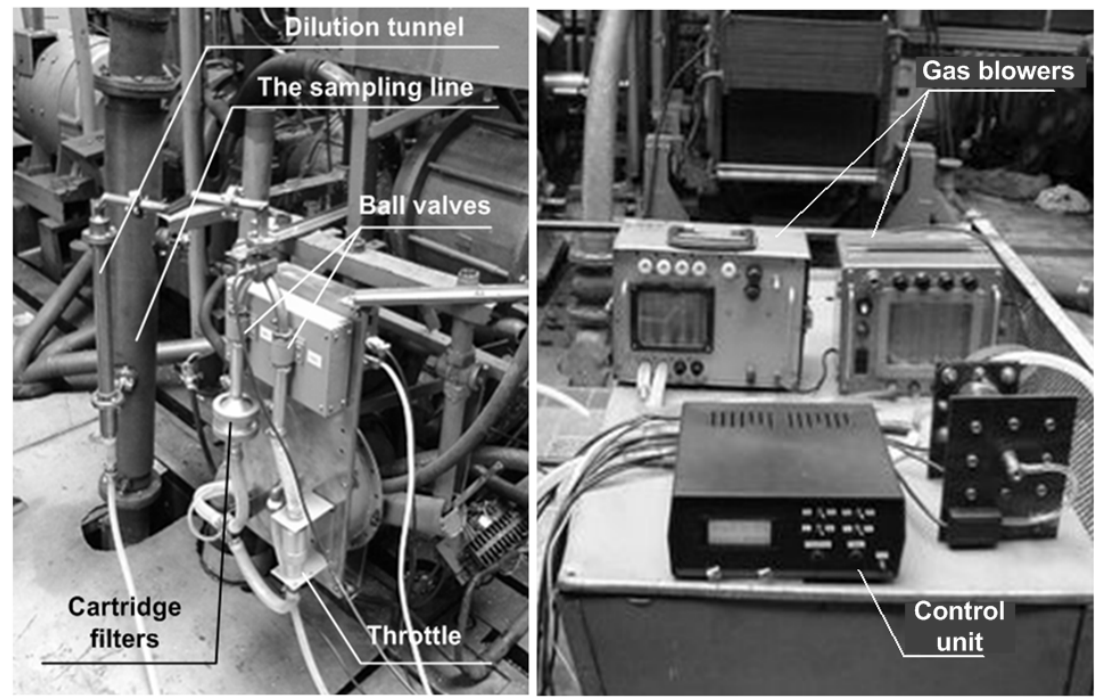

Figure 3. General view of microtunnels MKT-2 at the diesel engine stand $4 \mathrm{ChN12/14}$ 
b) a system of dilution of EG, the components of which are:

- dilution tunnel - stainless steel pipeline with an internal diameter of $30 \mathrm{~mm}$ and a length of $300 \mathrm{~mm}$;

- a diaphragm installed at the entrance to the tunnel in order to improve the process of mixing the EG with air;

- gas blower, which has a capacity of $20 \ldots 120 \mathrm{l} / \mathrm{min}$ and performs the function of a sampling pump;

- meter expense of 2 gas flows: diluting air - a collector profiled along a circular arc with an inner diameter of $8 \mathrm{~mm}$ and diluted $\mathrm{EG}-\mathrm{a}$ normal nozzle with an inner diameter of $3 \mathrm{~mm}$;

c) PM sampling system, the elements of which are:

- sampling line - stainless steel pipeline with an inner diameter of $16 \mathrm{~mm}$ and a length of $950 \mathrm{~mm}$;

- regulators of the "bypass" and "sampling" - ball valves;

- the bypass main line, in which the throttle is installed, which equalizes the pressure in the bypass and working main lines;

- the working main line in which the cartridge with a filter for sampling is installed;

- a protective filter with a paper filter element that prevents contamination of the PM sampling pump;

2) an electronic control module is a microprocessor unit, which is connected to the PC, to which sensors and governing bodies MKT-2 microtunnel are connected; this module provides the fulfillment of the following operations:

- monitoring the displays of sensors and flowmeters of the sampling system;

- PM sampling process control - switching bypass and sampling modes;

- transfer of control and management functions of microtunnels to a PC, allows you to register, process and log measurement results;

3) a chamber for stabilization and weighing of filters (Figure 4), which provides the conditions for measuring PM mass established by regulatory documents; inside the camera there are:

- the air temperature control system in the range of $18-40{ }^{\circ} \mathrm{C}$ with an accuracy of $\pm 1^{\circ} \mathrm{C}$;

- a system for controlling relative humidity in the range of $40-90 \%$ with an accuracy of $\pm 3 \%$; 


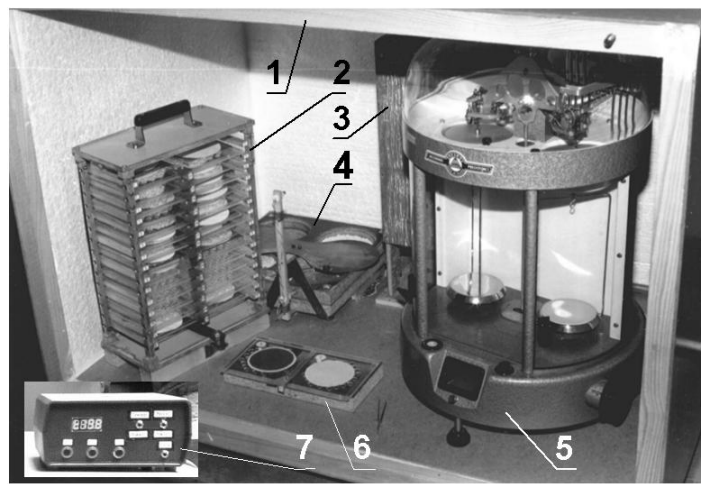

Figure 4. The main elements of the camera to stabilize and weigh the filters:

1 - housing; 2 - cartridge with filters; 3 - flue with fan and heater;

4 - humidity regulator; 5 - analyt-ical balance; 6 - stand for filters;

7 - electronic regulator of temperature and humidity conditions

- analytical balance with a weighing error of $\pm 0.01 \mathrm{mg}$;

- cassette for storage and transportation of working filters with a capacity of up to 30 pairs of filters;

- an electronic controller (control unit) for monitoring and controlling the temperature and humidity conditions of the camera modes; duration the continuous operation of the regulator is 36 hours.

The principle of operation of MKT-2 is as follows (Figure 5).

Part of EG with a mass flow rate of the $\mathrm{G}_{\text {exh }}^{\mathrm{t}}$ is taken from the exhaust pipe of the engine and fed through the pipeline to the dilution tunnel - DT, where it is mixed with atmospheric air. From the tunnel, through one of the ball valves, a stream of diluted EG with a $\mathrm{G}_{\text {sam }}$ mass flow rate enters either the bypass main line or the working channel, in which the cartridge with a working filter is installed. For sampling PM, glass fiber-based filters with a fluorocarbon coating are used with capture coefficient PM capture rates greater than $99 \%$. Working filters have an external diameter of 70 $\mathrm{mm}$, the speed of passage of the sample through them varies in the range of $35 \ldots 100 \mathrm{~cm} / \mathrm{s}$. The pressure drop across the filters in the final sampling phase does not exceed $25 \mathrm{kPa}$. The minimum allowable PM weight on the filter is $0.25 \mathrm{mg}$. When sampling PM, the temperature of the sample in front 


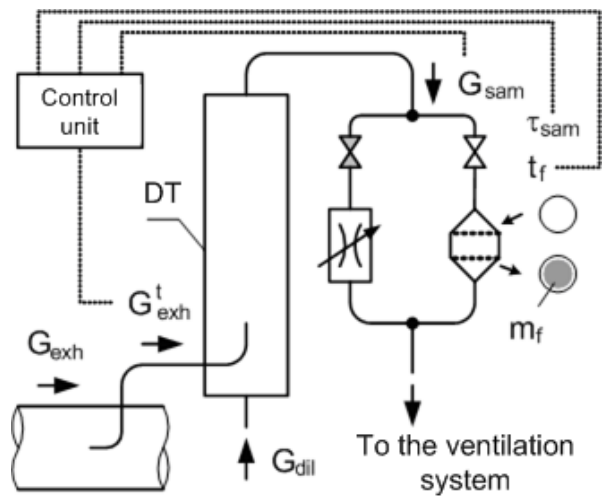

Figure 5. Schematic diagram of microtunnels MKT-2

of the filter $\mathrm{t}_{\mathrm{f}}$ does not exceed $52^{\circ} \mathrm{C}$. Ball valves, which determine the direction of sample flow in the sampling line, are always in the opposite states: when one is open, the other is closed and vice versa. When preparing the sample for analysis, the diluted EG flows through the bypass main line. With the help of a throttle installed in it, the pressure in the line is regulated so that at the time of switching the valves there is no hydraulic blow. During the PM sampling procedure, the entire diluted exhaust gas stream flows through the filter. At the same time, the duration of this procedure is fixed $-\tau_{\text {sam }}$.

After completion testing is measured the PM mass, $\mathrm{m}_{\mathrm{f}}$, as the mass gain of the working filter during the test. For control the parameters $G_{\text {exh }}^{t}, G_{\text {sam }}$, $\tau_{\text {sam }}, \mathrm{t}_{\mathrm{f}}$ and control ball valves an electronic module is used to.

The calculation of mass and volume concentrations $-c_{p t}$ and $C_{p p}$ mass $P T_{\text {mass }}$ and specific $-P T_{p}$ emissions of $P M$ is carried out using the formulas:

$$
c_{p t}=\frac{m_{f} \cdot 10^{-3}}{m_{\text {sam }}} \cdot q, \mathrm{~g} / \mathrm{kg}
$$

where $m_{f}-$ PM mass collected on the filter, mg;

$\mathrm{m}_{\text {sam }}$ - mass of sample diluted $\mathrm{EG}$, which passed through the filter, $\mathrm{kg}$;

$\mathrm{q}$ - the coefficient of dilution of EG with air in the tunnel, which is determined as the result of dividing the value of $\mathrm{G}_{\text {sam }}$ by $\mathrm{G}_{\text {exh}}^{\mathrm{t}}$;

$$
C_{p t}=c_{p t} \cdot \rho_{e x h}, \mathrm{~g} / \mathrm{mn}^{3},
$$

where $\rho_{\text {exh }}$ - the density EG of the diesel engine, $\mathrm{kg} / \mathrm{mn}^{3}$; 


$$
P T_{\text {mass }}=C_{p t} \cdot G_{e x h}, \mathrm{~g} / \mathrm{h},
$$

where $\mathrm{G}_{\text {exh }}$ - mass consumption of EG in the test mode, $\mathrm{kg} / \mathrm{h}$;

$$
P T_{\mathrm{p}}=\frac{P T_{\text {mass }}}{P}, \mathrm{~g} / \mathrm{kWh},
$$

where $\mathrm{P}$ - effective diesel power, $\mathrm{kW}$ :

$$
P=\frac{n \cdot M_{k}}{9550}-P_{a u x}, \mathrm{~kW},
$$

where $\mathrm{n}$ - the number of revolutions of the engine crankshaft, $\mathrm{min}^{-1}$;

$\mathrm{M}_{\mathrm{k}}$ - torque on the motor shaft, $\mathrm{N} \cdot \mathrm{m}$;

$\mathrm{P}_{\text {aux }}$ - power of auxiliary equipment, $\mathrm{kW}$.

Technical characteristics of the MKT-2 microtunnel:

- the accuracy of measurements of concentrations and PM emissions is characterized by instrumental errors in determining the values of $\mathrm{C}_{\mathrm{pt}}, \mathrm{PT}_{\text {mass }}$ and $\mathrm{PT}_{\mathrm{p}}$, which are $3 \ldots 10 \%$ (Table 1);

- the speed of the PM sampling system is characterized by the duration of preparation of the microtunnel for measurements, which does not exceed 5 minutes, and the duration of the PM sampling procedure, which in different modes of diesel operation is from 1 to 7 minutes;

- overall dimensions $(\mathrm{L}, \mathrm{B}, \mathrm{H})-500 \times 300 \times 1200 \mathrm{~mm}$, weight $-40 \mathrm{~kg}$.

\begin{tabular}{|c|c|c|c|}
\hline \multirow{3}{*}{ Parameter } & \multicolumn{3}{|c|}{ Relative measurement error } \\
\hline & \multirow{2}{*}{$\begin{array}{l}\text { Provided by } \\
\text { MKT-2 }\end{array}$} & \multicolumn{2}{|c|}{ Requirements of standard ISO 8178} \\
\hline & & $\begin{array}{l}\text { Measurements at } \\
\text { the stand }\end{array}$ & $\begin{array}{l}\text { Measurements on } \\
\text { the object }\end{array}$ \\
\hline Mf & $2.7 \%$ & \multicolumn{2}{|c|}{$2.7 \%$} \\
\hline$\tau^{\mathrm{pt}}{ }_{\mathrm{sam}}$ & $0.25 \%$ & \multicolumn{2}{|c|}{---} \\
\hline $\mathrm{G}_{\mathrm{exh}}$ & $1.7 \%$ & $4 \%$ & $5 \%$ \\
\hline $\mathrm{G}_{\mathrm{sam}}$ & $0.8 \%$ & \multicolumn{2}{|c|}{$2 \%$} \\
\hline $\mathrm{G}_{\mathrm{dil}}$ & $0.8 \%$ & \multicolumn{2}{|c|}{$2 \%$} \\
\hline $\mathrm{P}$ & $2 \%$ of the $P_{\text {nom }}$ & $2 \%$ of the $P_{\text {nom }}$ & $5 \%$ of the $P_{\text {nom }}$ \\
\hline $\mathrm{PT}_{\text {mass }}$ & $5.1 \%$ & $6.0 \%$ & $8.5 \%$ \\
\hline
\end{tabular}

Table 1

Microtunnel accuracy characteristic of MKT-2 


\section{Study of PM content in EG at steady-state diesel modes}

Based on the experimental setup described above, studies have been conducted in order to establish and analyze mathematical models that describe the influence of parameters that determine the stable operating modes of diesel on volumetric concentrations $-\mathrm{C}_{\mathrm{pt}}\left(\mathrm{g} / \mathrm{mn}^{3}\right)$, mass emissions $-\mathrm{PT}_{\text {mass }}(\mathrm{g} / \mathrm{h})$ and specific emissions $-\mathrm{PT}_{\mathrm{p}}(\mathrm{g} / \mathrm{kWh}) \mathrm{PM}$. For this, the following tasks have been solved:

- the choice of control steady-state modes for research is characterized by two parameters: the number of revolutions of the engine crankshaft $\mathrm{n}\left(\mathrm{min}^{-1}\right)$ and the load $-\mathrm{L}(\%$ of maximum torque at current $\mathrm{n})$;

- measurement of the values of $\mathrm{C}_{\mathrm{pt}}, \mathrm{PT}_{\text {mass }}$ and $\mathrm{PT}_{\mathrm{p}}$ when the diesel engine is in control test modes using MKT-2,

- establishment of regression dependences, reflecting the influence of the parameters $\mathrm{n}$ and $\mathrm{L}$ on the values of $\mathrm{C}_{\mathrm{pt}}, \mathrm{PT}_{\text {mass }}$ and $\mathrm{PT}_{\mathrm{p}}$;

- analysis of the results and development of recommendations for their use.

The choice of control modes of testing, measuring concentrations and emissions of PM. For research, a 2-factor plan of the $3 \times 4$ experiment has been chosen, in which the maximum operational ranges of variation of parameters $\mathrm{n}$ and $\mathrm{L}$ with the uniform nature of their changes are reflected. This plan includes 12 steady-state operating modes of the $4 \mathrm{ChN} 12 / 14$ diesel engine with 3 levels of variation of the parameter $\mathrm{n}-1000,1500$ and $2000 \mathrm{~min}^{-1}$ and 4 levels of variation of the parameter $\mathrm{L}-25,50,75$ and $100 \%$.

In each control mode, the values of $\mathrm{C}_{\mathrm{pt}}, \mathrm{PT}_{\text {mass }}$, and $\mathrm{PT}_{\mathrm{p}}$ have been experimentally determined (Table 2). The reproducibility errors of measurements of these values ranged from $4 \ldots 7 \%$ - with a significant content of PM in EG (in modes with a load of 50-100\%) to $14 \ldots 17 \%$ - with a small content of PM in EG (in modes with a load of $0-25 \%$ ). The average values of the measurement errors of $\mathrm{C}_{\mathrm{pt}}, \mathrm{PT}_{\text {mass }}$, and $\mathrm{PT}_{\mathrm{p}}$ amounted to $8 \ldots 10 \%$ or \pm 0.005 $\mathrm{g} / \mathrm{mn}^{3}, \pm 1.78 \mathrm{~g} / \mathrm{h}$, and $\pm 0.04 \mathrm{~g} / \mathrm{kWh}$, respectively.

Establishment of the dependences of the values of $\mathrm{C}_{\mathrm{pt}}, \mathrm{PT}_{\text {mass }}$ and $\mathbf{P T}_{\mathrm{p}}$ on the parameters that determine the test mode. Experimental data on the concentration and emissions of PM in the control diesel operation modes have been used to determine the regression dependencies

$$
Y=f(n, L),
$$

where $\mathrm{Y}$ - a generalized designation of quantities which are controlled $\mathrm{C}_{\mathrm{pt}}, \mathrm{PT}_{\text {mass }}$ or $\mathrm{PT}_{\mathrm{p}}$; 
The results of studies of the content of PM in EG in control modes of diesel operation $4 \mathrm{ChN12/14}$

\begin{tabular}{|c|c|c|c|c|c|c|c|}
\hline \multicolumn{5}{|c|}{ Control test modes } & \multicolumn{3}{|c|}{ Measurement results } \\
\hline № mode & $\mathbf{n}, \mathbf{m i n}^{-1}$ & $\begin{array}{c}\mathbf{M}_{\mathbf{k}}, \\
\mathbf{N} \cdot \mathbf{m} \\
\end{array}$ & $\mathbf{P}_{\mathrm{e}}, \mathrm{kW}$ & $\mathrm{L}, \%$ & $\begin{array}{c}\mathrm{C}_{\mathrm{pt}} \\
\mathrm{g} / \mathbf{m n}^{3}\end{array}$ & $\begin{array}{c}\mathbf{P T} \mathbf{T}_{\text {mass }}, \\
\mathrm{g} / \mathbf{h}\end{array}$ & $\begin{array}{c}\mathbf{P T}_{\mathrm{p}}, \\
\mathrm{g} / \mathbf{k W h}\end{array}$ \\
\hline 1 & 2000 & 478.0 & 100.1 & 100 & 0.063 & 37.82 & 0.378 \\
\hline 2 & 2000 & 351.4 & 73.6 & 73.5 & 0.038 & 20.82 & 0.283 \\
\hline 3 & 2000 & 239.0 & 50.05 & 50 & 0.042 & 20.06 & 0.401 \\
\hline 4 & 2000 & 119.5 & 25.02 & 25 & 0.062 & 25.32 & 1.012 \\
\hline 5 & 1500 & 541.2 & 85.01 & 100 & 0.074 & 30.10 & 0.354 \\
\hline 6 & 1500 & 407.7 & 64.03 & 75.3 & 0.044 & 15.61 & 0.244 \\
\hline 7 & 1500 & 274.8 & 42.95 & 50.5 & 0.034 & 11.07 & 0.258 \\
\hline 8 & 1500 & 140.6 & 22.08 & 26.0 & 0.023 & 6.88 & 0.311 \\
\hline 9 & 1000 & 379.6 & 39.74 & 100 & 0.125 & 24.42 & 0.614 \\
\hline 10 & 1000 & 281.2 & 29.44 & 74.1 & 0.071 & 13.06 & 0.444 \\
\hline 11 & 1000 & 189.1 & 19.8 & 49.8 & 0.030 & 5.50 & 0.278 \\
\hline 12 & 1000 & 92.1 & 9.642 & 24.3 & 0.019 & 3.48 & 0.361 \\
\hline
\end{tabular}

$\mathrm{f}(\mathrm{n}, \mathrm{L})$ - the desired function of 2 variables $-\mathrm{n}$ and $\mathrm{L}$.

Since the view of the regression equation (6) has not been known beforehand, 3 dependencies have been selected for analysis, the most reliable of which have been determined:

- dependence 1:

$$
Y=K_{1} \cdot f_{n}(Y) \cdot f_{L}(Y),
$$

where $\mathrm{K}_{1}$ - a constant coefficient;

$f_{n}(Y)$ and $f_{L}(Y)$ - functions of one variable characterizing the influence of each of the parameters $-\mathrm{n}$ and $\mathrm{L}$ on the value of $\mathrm{Y}$;

- dependence 2:

$$
Y=K_{2}+F_{n}(Y)+F_{L}(Y),
$$

where $\mathrm{K}_{2}$ - a constant coefficient;

$\mathrm{F}_{\mathrm{n}}(\mathrm{Y})$ and $\mathrm{F}_{\mathrm{L}}(\mathrm{Y})$ - functions of one variable characterizing the influence of $\mathrm{n}$ and $\mathrm{L}$ on the value of $\mathrm{Y}$;

- dependence 3 - polynomial of the 2 nd order:

$$
Y=A_{0}+A_{1} \cdot n+A_{2} \cdot L+A_{11} \cdot n^{2}+A_{22} \cdot L^{2}+A_{12} \cdot n \cdot L,
$$

where $\mathrm{A}_{0}, \mathrm{~A}_{1}, \mathrm{~A}_{2}, \mathrm{~A}_{11}, \mathrm{~A}_{22}, \mathrm{~A}_{12}-\mathrm{a}$ constant coefficients. 
The choice of the given dependences is due to the wide scope of their use, ease of determination, and convenience in analysis and practical use. Therefore, dependence 1 is successfully used in mathematical models to determine the fuel and economic parameters of ICEs, which were constructed based on the results of multivariate experiments [10].

The root mean square (RMS) deviations of the calculated data from the corresponding experimental values, expressed in absolute units with a dimension of $\mathrm{Y}-\mathrm{S}_{\mathrm{Y}}$ and in relative units $(\%)-\mathrm{S}_{\mathrm{Y}}$, have been considered as criteria for the accuracy of the studied dependences [11]:

$$
S_{Y}=\sqrt{\frac{\sum_{i=1}^{m}\left(Y_{r i}-Y_{i}\right)^{2}}{m \cdot(m-1)}},
$$

where $\mathrm{Y}_{\mathrm{ri}}$ - the value of $\mathrm{Y}$, which has been determined by the selected regression equation in the $\mathrm{i}$-th test mode;

$\mathrm{Y}_{\mathrm{i}}-$ the experimental value of $\mathrm{Y}$ in the $\mathrm{i}$-th mode;

$\mathrm{m}=12-$ the number of control modes;

$$
s_{Y}=\frac{S_{Y}}{Y_{a}} \cdot 100 \%,
$$

where $\mathrm{Y}_{\mathrm{a}}$ - the average values of the studied value of $\mathrm{Y}$, which have been determined as arithmetic average of 12 measurements of $Y_{i}$ and are \pm $0.052 \mathrm{~g} / \mathrm{mn}^{3}, \pm 17.85 \mathrm{~g} / \mathrm{h}$ and $\pm 0.411 \mathrm{~g} / \mathrm{kWh}$, respectively for $\mathrm{C}_{\mathrm{pt}}, \mathrm{PT}_{\text {mass }}$ and $\mathrm{PT}_{\mathrm{p}}$.

The coefficients $\mathrm{K}_{1}, \mathrm{~K}_{2}$ and the functions $\mathrm{f}_{\mathrm{n}}(\mathrm{Y}), \mathrm{f}_{\mathrm{L}}(\mathrm{Y})$ and $\mathrm{F}_{\mathrm{n}}(\mathrm{Y}), \mathrm{F}_{\mathrm{L}}(\mathrm{Y})$ in expressions (7) and (8) have been determined by the method described in [10], and for the coefficients $A_{i}$ of the dependence (9) have been calculated using the technique presented in [12] (Table 3, Figure 6, 7).

For each dependence, using the expressions (10) and (11), the values of $\mathrm{S}_{\mathrm{Y}}$ and $\mathrm{s}_{\mathrm{Y}}$ were established (Table 4).

As can be seen from the Table 4, dependencies 1 and 2 do not have sufficient accuracy, since the $\mathrm{s}_{\mathrm{Y}}$ value for them is $29.3 \ldots 38.6 \%$ (with the exception of the $\mathrm{s}_{\mathrm{PT} \text { mass }}$ value $=14.1 \%$ for dependence 2 ).

For the polynomial dependence 3 , the values of $\mathrm{s}_{\mathrm{Cpt}}$ and $\mathrm{s}_{\mathrm{PTmass}}$ are comparable with the average experimental error, and the value of $\mathrm{s}_{\mathrm{PT}}$ exceeds it by 1.9 times. Thus, from 3 considered dependences, the most reliable is the dependence 3 - a polynomial model of the 2 nd order (9), which allows a fairly accurate estimate of the influence of the parameters $n$ and $L$ on the 
Chapter «Engineering sciences»

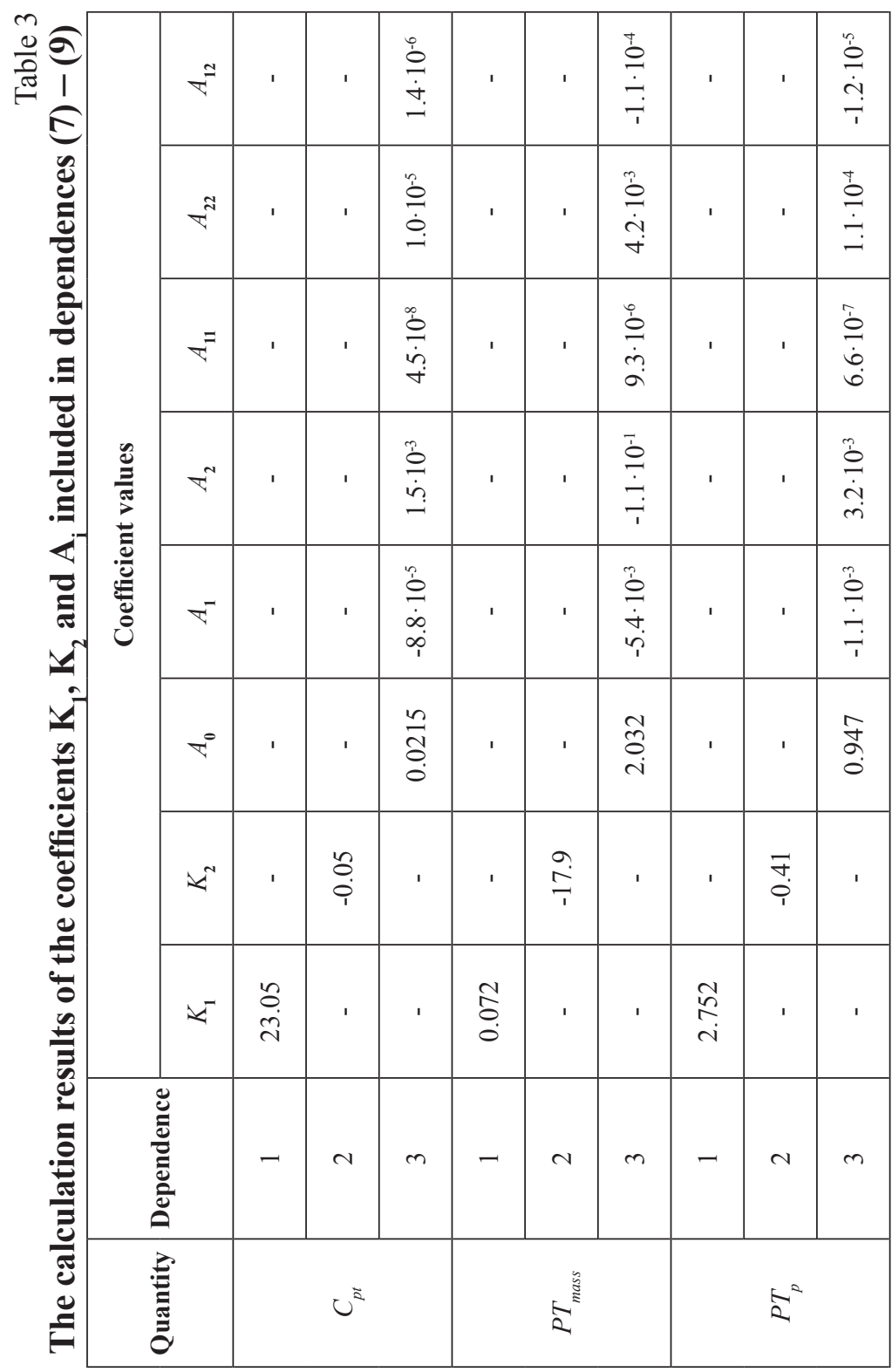




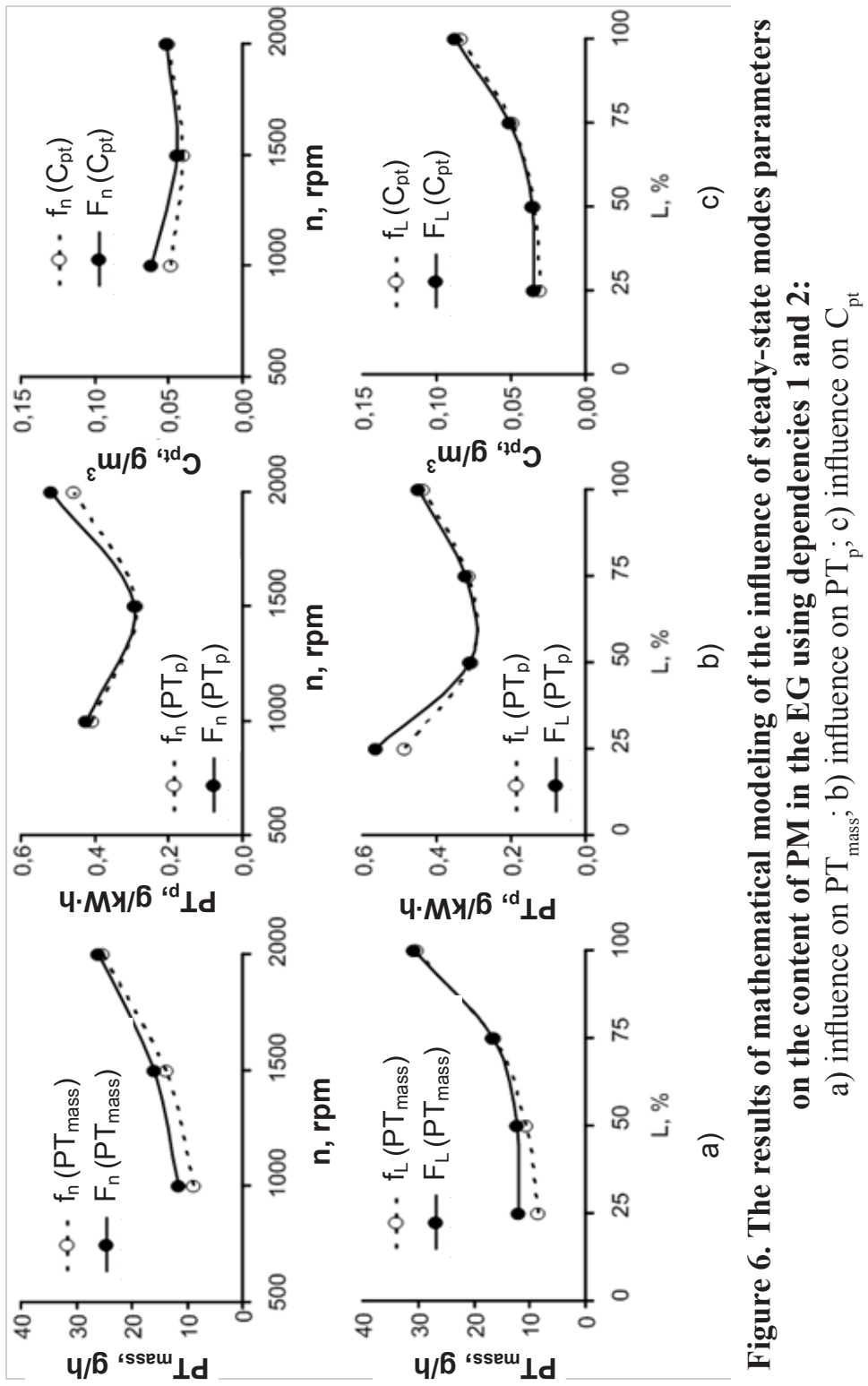




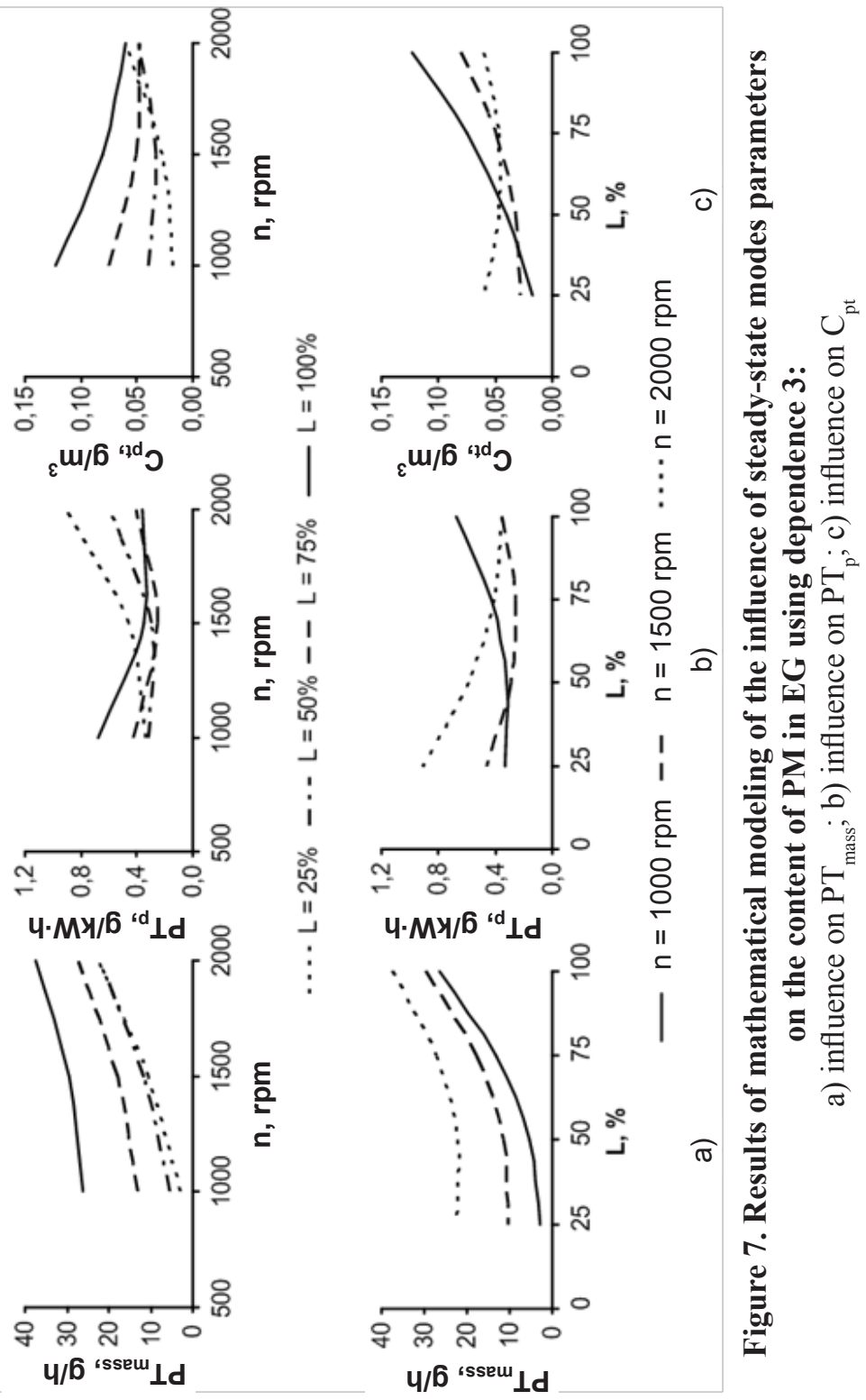


Table 4

Absolute and relative values RMS of standard deviations of dependencies (7) - (9)

\begin{tabular}{|c|c|c|c|c|c|c|}
\hline \multirow{2}{*}{ Dependence } & \multicolumn{3}{|c|}{$\mathbf{S}_{\mathbf{Y}}$} & \multicolumn{3}{|c|}{$\mathbf{S}_{\mathbf{Y}}, \mathbf{\%}$} \\
\cline { 2 - 7 } & $\begin{array}{c}\mathbf{S}_{\mathbf{C p t}_{\mathbf{p}}} \\
\mathbf{g} / \mathbf{m n}^{\mathbf{3}}\end{array}$ & $\begin{array}{c}\mathbf{S}_{\mathbf{P T m a s s}} \\
\mathbf{g} / \mathbf{h}\end{array}$ & $\begin{array}{c}\mathbf{S}_{\mathbf{P T p}} \\
\mathbf{g} / \mathbf{k W h}\end{array}$ & $\mathbf{s}_{\mathbf{C p t}}$ & $\mathbf{S}_{\text {PTmass }}$ & $\mathbf{S}_{\text {PTp }}$ \\
\hline 1 & 0.0181 & 5.27 & 0.121 & 34.7 & 29.5 & 29.3 \\
\hline 2 & 0.0176 & 2.52 & 0.159 & 33.7 & 14.1 & 38.6 \\
\hline 3 & 0.0042 & 2.02 & 0.077 & 8.1 & 11.3 & 18.8 \\
\hline
\end{tabular}

values of $\mathrm{C}_{\mathrm{pt}}$ and $\mathrm{PT}_{\text {mass }}$ and can be used for a rough estimate of the $\mathrm{PT}_{\mathrm{p}}$ value.

Analysis of the research results shows the following (see. Figure 7):

a) the influence operating mode of the diesel on the PM concentration:

- the value of $\mathrm{C}_{\mathrm{pt}}$ with increasing $\mathrm{n}$ from 1000 to $2000 \mathrm{~min}^{-1}$ varies depending on the value of the load: at $\mathrm{L}=25 \%$ it increases from $0.02 \mathrm{~g} / \mathrm{mn}^{3}$ (minimum value) to $0.06 \mathrm{~g} / \mathrm{mn}^{3}$, at $\mathrm{L}=100 \%$ - decreases from $0.12 \mathrm{~g} / \mathrm{mn}^{3}$ (maximum value) to $0.06 \mathrm{~g} / \mathrm{mn}^{3}$; at the same time with an increase in $\mathrm{L}$ from 25 to $100 \%$, the growing dependence of $\mathrm{C}_{\mathrm{pt}}$ on $\mathrm{n}$ gradually turns into a downward dependence.

b) the influence operating mode of the diesel on mass emission of PM:

- the value of $\mathrm{PT}_{\text {mass }}$ with increasing $\mathrm{n}$ from 1000 to $2000 \mathrm{~min}^{-1}$ at a fixed value of torque increases with a close to linear dependence with an angular coefficient of $0.015(\mathrm{~g} / \mathrm{h}) / \mathrm{min}^{-1}$;

- an increase in L from 25 to $60 \%$ has little effect on the growth of $\mathrm{PT}_{\text {mass }}$, but an increase in load in the range of $60 \ldots 100 \%$ leads to a significant increase in PM emission - by 1.7 ... 3.5 times;

- the minimum value of $\mathrm{PT}_{\text {mass }}-3.0 \mathrm{~g} / \mathrm{h}$ is observed in the mode with $\mathrm{n}$ $=1000 \mathrm{~min}^{-1}, \mathrm{~L}=25 \%$, the maximum value $-37.4 \mathrm{~g} / \mathrm{h}-$ in the mode with $\mathrm{n}=2000 \mathrm{~min}^{-1}, \mathrm{~L}=100 \%$;

c) the influence mode operation of the diesel on the specific emission of PM:

- the $\mathrm{PT}_{\mathrm{p}}$ value with increasing $\mathrm{n}$ from 1000 to $2000 \mathrm{~min}^{-1}$ changes depending on the load: at $\mathrm{L}=25 \%$ it increases from 0.34 to $0.91 \mathrm{~g} / \mathrm{kWh}$, at $\mathrm{L}=100 \%$ it decreases from 0,67 to $0.36 \mathrm{~g} / \mathrm{kWh}$; in this case, with an increase in L from 25 to $100 \%$, the growing dependence of $\mathrm{PT}_{\mathrm{p}}$ on $\mathrm{n}$ gradually turns into a downward dependence; 
- the minimum value of $\mathrm{PT}_{\mathrm{p}}-0.25 \mathrm{~g} / \mathrm{kWh}$ is observed at $\mathrm{n}=1500 \mathrm{~min}^{-1}$, $\mathrm{L}=75 \%$, the maximum value $-0.91 \mathrm{~g} / \mathrm{kWh}-$ at $\mathrm{n}=2000 \mathrm{~min}^{-1}, \mathrm{~L}=25 \%$.

Recommendations for using research results. Establishing dependencies to reflect the influence of diesel operating mode on the values of $\mathrm{C}_{\mathrm{pt}}$, $\mathrm{PT}_{\text {mass }}$ and $\mathrm{PT}_{\mathrm{p}}$ can be used both for indirect estimation of their values and for determining the minimum duration of PM sampling in dilution tunnels $-\tau_{\min }$, at which the accuracy of these measuring systems is ensured [13]. So, when measuring the mass concentration of PM at a steady test mode, the value can be determined by the formula

$$
\tau_{\text {man }}=\frac{m_{f(\min )}}{\left(c_{p t(a)}-\Delta c_{p t(a)}\right) \cdot G_{\text {sam }(\max )}} \cdot q_{\text {min }}, \mathrm{S}
$$

where $\mathrm{m}_{\mathrm{f}(\min )}=0.25 \mathrm{mg}$ - the minimum allowable mass of PM particles on the filter;

$\mathrm{c}_{\mathrm{pt}(\mathrm{a})}$ - the calculated value of the mass concentration of PM in the EG, determined using the established regression dependence, $\mathrm{g} / \mathrm{kg}$;

$\Delta c_{p t(a)}$ - the error of indirect determination of $c_{p t(a)}$, which is determined by the 2 -sigma rule as $2 \cdot \mathrm{S}_{\mathrm{Cpt}}[14]$;

$\mathrm{G}_{\text {sam(max) }}=2.5 \mathrm{~g} / \mathrm{s}-$ the maximum allowable mass consumption samples diluted $\mathrm{EG}$ in the tunnel;

$\mathrm{q}_{\min }=4$ - the minimum allowable value of the coefficient of dilution of EG.

Formula (12) is obtained on the basis of dependence (1). Similarly, on the basis of dependences (2) - (4), formulas can be established for determining the duration $\tau_{\min }$ when measuring the values $\tau_{\min }$ of $\mathrm{C}_{\mathrm{pt}}, \mathrm{PT}_{\text {mass }}$ and $\mathrm{PT}_{\mathrm{p}}$.

\section{Study of PM content in EG at unsteady diesel modes}

In the mathematical models, not only the values of $n$ and $L$, but also the rate of change of these values in time $-\Delta \mathrm{n} / \Delta \mathrm{t}$ and $\Delta \mathrm{L} / \Delta \mathrm{t}$ are used to indirectly estimate PM emissions from EG in unsteady diesel operating modes with parameters that determine the test mode. Moreover, to improve the convenience of processing and analyzing experimental data, the parameters characterizing the engine operating mode are presented in dimensionless form:

$$
\begin{gathered}
\bar{n}_{i}=\frac{n_{i}-n_{\text {idle }}}{n_{\text {nom }}-n_{\text {idle }}}, \\
\bar{L}_{i}=\frac{M_{k i}}{M_{k(\max ) i}},
\end{gathered}
$$


where $\bar{n}_{i}$ and $n_{\mathrm{i}}$ - the dimensionless and absolute $\left(\mathrm{min}^{-1}\right)$ value of the number of revolutions of the engine crankshaft in the i-th test mode, respectively;

$\mathrm{n}_{\text {idle }}$ and $\mathrm{n}_{\text {nom }}$ - the number of revolutions of the engine shaft at idle and rated power mode, respectively;

$\bar{L}_{i}$ та $\mathrm{L}_{\mathrm{i}}$ - dimensionless and absolute (\%) value of the load in the $\mathrm{i}$-th test mode, respectively;

$\mathrm{M}_{\mathrm{ki}}$ - torque on the motor shaft in i-th mode;

$\mathrm{M}_{\mathrm{k}(\max ) \mathrm{i}}$ - the maximum torque on the motor shaft at its rotation speed $n_{\mathrm{i}}$.

The results of experimental studies of the PM content in the EG for different diesel operating modes show that for indirect determination of PM concentrations in unstable test modes $-\mathrm{c}_{\mathrm{pt}}^{\mathrm{un}}$ the formula can be used

$c_{p t}^{u n}=c_{p t}^{s t}+\Delta c_{p t}, \mathrm{~g} / \mathrm{kg},(13)$

where $\mathrm{c}^{\mathrm{st}}$ pt - the mass concentration of PM in the EG of the diesel engine at the steady-state test mode, which is characterized by the parameters $\mathrm{n}(\bar{n})$ and $\mathrm{L}(\bar{L})$;

$\Delta c_{p t}$ - the increase in the mass concentration of PM, which occurs during the transition from a constant to an unstable mode of operation of a diesel engine and is characterized by the quantities $\Delta \mathrm{n} / \Delta \mathrm{t}(\Delta \overline{\mathrm{n}} / \Delta \mathrm{t})$ and $\Delta \mathrm{L} / \Delta \mathrm{t}(\Delta \overline{\mathrm{L}} / \Delta \mathrm{t})$.

During tests of the $4 \mathrm{ChN12} / 14$ diesel engine using MKT-2 microtunnels, a regression dependence has been established to determine $\Delta \mathrm{c}^{\mathrm{un}}{ }_{\mathrm{pt}}$ when varying the parameters $\mathrm{n}$ and $\mathrm{L}$ in the ranges: $\mathrm{n}=1250 \ldots 2000 \mathrm{~min}^{-1}$ $(\bar{n}=0.4 \ldots 0,8)$ and $\mathrm{L}=30 \ldots 100 \%(\bar{L}=0.3 \ldots 1.0)$ with the duration of unstable modes $\Delta \mathrm{t}=10 \ldots 30 \mathrm{~s}$. Based on the analysis of experimental data, the type of this dependence has been selected - a polynomial of the first order:

$$
\Delta \mathrm{c}_{p t}=K_{n}\left(\frac{\Delta \bar{n}}{\Delta t}\right)+K_{L}\left(\frac{\Delta \bar{L}}{\Delta t}\right), \mathrm{g} / \mathrm{kg}
$$

where $\mathrm{K}_{\mathrm{n}}$ та $\mathrm{K}_{\mathrm{L}}$ - the coefficients that have been determined during the experiment;

$(\Delta \overline{\mathrm{n}}, \Delta \overline{\mathrm{L}}$ - relative increments of quantities $\bar{n}$ and $\bar{L}$ during the unstable regime.

The procedure for determining the dependence coefficients (14) consisted of 3 test cycles that have been performed sequentially one after another (Figure 8):

A - a cycle of 5 steady-state diesel modes; 


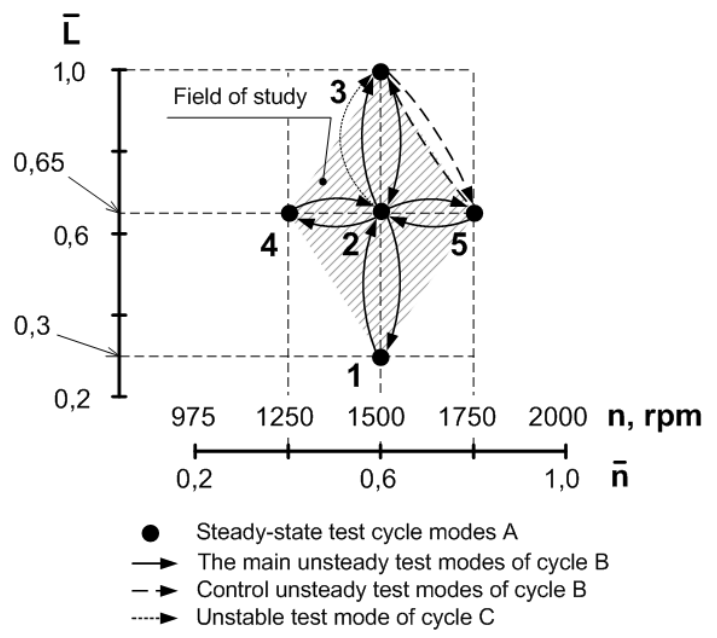

Figure 8. The experimental research plan the influence of unstable operating modes of the $4 \mathrm{ChN12} / 14$ diesel engine on the content of PM in EG

B - a cycle of 10 unstable diesel operation modes with a duration of $\Delta t=21.5 \pm 1 \mathrm{~s}$; this cycle consists of 4 pairs of main modes with the same values in each pair of one of the values $-\Delta \overline{\mathrm{n}}$ or $\Delta \overline{\mathrm{L}}$ either with a zero value of another value and 2 control modes with different values of $\Delta \overline{\mathrm{n}}$ and $\Delta \overline{\mathrm{L}}$;

$\mathbf{C}$ - a cycle consisting of 3 repeating unsteady modes, in which the values $\Delta \overline{\mathrm{n}}$ and $\Delta \overline{\mathrm{L}}$ have not changes and have been $\Delta \overline{\mathrm{n}}=0$ and $\Delta \overline{\mathrm{L}}=0.35$, and the duration of the $\Delta t$ regime has changed and took the value of 10,20 , and $30 \mathrm{~s}$.

As a result of the execution of cycle $\mathrm{A}$, the PM concentration values $\mathrm{c}_{\mathrm{pt}}^{\mathrm{st}}$ have been measured $-\mathrm{c}_{\mathrm{pt}}^{\mathrm{st}}$, which corresponds to the initial and final values $\bar{n}$ and $\bar{L}$ of the parameters and unstable test modes of cycles B and $\mathrm{C}$ in the ranges of variation $\bar{n}=0.4 \ldots 0.8$ and $\bar{L}=0.3 \ldots 1,0$.

As a result of the execution of cycle $B$ in the main test modes, the coefficients have been determined:

$-\mathrm{K}_{\mathrm{L}}$ with an increase in $\mathrm{L}$ by $35 \%(\Delta \overline{\mathrm{L}}=0.35)$ at various initial values of $n$ (modes $1 \rightarrow 2$ and $2 \rightarrow 3$ );

$-\mathrm{K}_{\mathrm{L}}$ with a decrease in $\mathrm{L}$ by $35 \%(\Delta \overline{\mathrm{L}}=-0.35)$ for various initial values of $\mathrm{n}$ (modes $3 \rightarrow 2$ and $2 \rightarrow 1$ ); 
$-\mathrm{K}_{\mathrm{n}}$ when $\mathrm{n}$ grows by $250 \mathrm{~min}^{-1}(\Delta \overline{\mathrm{n}}=0.2)$ at various initial values of $\mathrm{L}$ (modes $4 \rightarrow 2$ and $2 \rightarrow 5$ );

$-K_{n}$ when $n$ decreases by $250 \min ^{-1}(\Delta \bar{n}=-0.2)$ at various initial values of $\mathrm{L}$ (modes $5 \rightarrow 2$ and $2 \rightarrow 4$ ).

To determine the coefficients $\mathrm{K}_{\mathrm{n}}$ and $\mathrm{K}_{\mathrm{L}}$, the formulas have been used:

$$
\begin{aligned}
K_{n} & =\frac{\Delta c_{\mathrm{pt}(\mathrm{ex})}}{(\Delta \bar{n} / \Delta t)},(\mathrm{g} \cdot \mathrm{c}) / \mathrm{kg}, \\
K_{L} & =\frac{\Delta c_{\mathrm{pt}(\mathrm{ex})}}{(\Delta \bar{L} / \Delta t)},(\mathrm{g} \cdot \mathrm{s}) /(\mathrm{kg}),
\end{aligned}
$$

where $\Delta \mathrm{c}_{\mathrm{pt( \textrm {ex } )}}$ - the deviation of the mass concentration of PM determined at the unsteady and corresponding to it steady-state modes of diesel operation; the first value is determined experimentally using MKT-2 and calculated using formula (1), and the second is taken to be equal to the average value of $2 \mathrm{PM}$ concentrations at the steady-state modes, from which the unstable mode begins and ends, and determined during cycle A.

In the course of processing the results of the execution of cycle $\mathrm{B}$, for each pair of the main test modes indicated above, the average value of the coefficient that has been studied, $\mathrm{K}_{\mathrm{n}}$ or $\mathrm{K}_{\mathrm{L}}$, has been calculated and its RMS has been estimated.

In the control test modes of cycle $\mathrm{B}$ (modes $3 \rightarrow 5$ and $5 \rightarrow 3$ ), the accuracy of determination of $\mathrm{c}^{\mathrm{un}}{ }_{\mathrm{pt}}$ has been estimated using dependence (13) with simultaneous changes in the parameters $\Delta \overline{\mathrm{n}}$ and $\Delta \overline{\mathrm{L}}$.

As a result of cycle $\mathrm{C}$, the following values have been determined: the average value of the coefficient $\mathrm{K}_{\mathrm{L}}-\mathrm{K}_{\mathrm{L}(\mathrm{m})}$ and its $\mathrm{RMS}-\mathrm{S}_{\mathrm{KL}}$ with an increase in $\mathrm{L}$ by $35 \%$ at $\mathrm{n}=1500 \mathrm{~min}^{-1}$ (mode $2 \rightarrow 3 \Delta \overline{\mathrm{n}}=0, \Delta \overline{\mathrm{L}}=0.35$ ) in the range varying the duration of the unsteady mode $\Delta t=10 \ldots 30 \mathrm{~s}$; in this case, the formula has been used:

$$
K_{L(m)}=\frac{1}{3} \cdot \sum_{i=1}^{n} K_{L i}
$$

where $\mathrm{i}$ - the index of the test mode;

$\mathrm{n}=3$ - the number of modes in the test cycle $\mathrm{C}$;

$$
S_{K_{L}}=\sqrt{\frac{\sum_{i=1}^{n}\left(K_{L(m)}-K_{L i}\right)^{2}}{n \cdot(n-1)} .}
$$


Research results and their analysis. During the cycles A, B and C using MKT-2, concentration the PM in the EG at steady $-\mathrm{c}^{\mathrm{st}}$ and unsteady $\mathrm{c}^{\mathrm{un}}$ pt operating modes of the diesel engine $4 \mathrm{ChN} 12 / 14$ has been determined and and the coefficients $K_{n}$ and $K_{L}$ of the dependence (14) have been established (Tables 5, 6, Figure 9, 10).

Table 5

Results of studies of $\mathrm{c}^{\mathrm{st}}{ }_{\mathrm{pt}}$ concentrations during cycle $\mathrm{A}$

\begin{tabular}{|c|c|c|c|c|c|c|c|c|c|}
\hline \multirow[b]{2}{*}{ Mode } & \multicolumn{3}{|c|}{ Parameters mode } & \multicolumn{6}{|c|}{ Results of measurements and calculations } \\
\hline & $\begin{array}{c}\text { n, } \\
\min ^{-1} \\
\text { (n) }\end{array}$ & $\begin{array}{c}\mathbf{M}_{k}, \\
\mathbf{N} \cdot \mathbf{m} \\
(\mathbf{L})\end{array}$ & $\underset{\mathbf{k W}}{\mathbf{P}_{\mathrm{e}}}$ & $\begin{array}{l}\mathrm{G}_{\text {exh}}, \\
\mathrm{kg} / \mathrm{h}\end{array}$ & $\mathbf{q}$ & $\tau_{\mathrm{sam}}$, & $\begin{array}{c}\mathbf{G}_{\text {sam }}, g / \mathbf{g} \\
\left(\mathbf{m}_{\text {sam }}, g\right)\end{array}$ & $\begin{array}{l}\mathrm{m}_{\mathrm{f}} \\
\mathrm{mg}\end{array}$ & $\begin{array}{l}\mathbf{c}^{\mathrm{st}}{ }_{\mathrm{pt}} \\
\mathbf{g} / \mathbf{k g}\end{array}$ \\
\hline 1 & $\begin{array}{l}1500 \\
(0.6)\end{array}$ & $\begin{array}{l}175,7 \\
(0.3)\end{array}$ & 27.6 & 403.6 & 7.13 & 271.1 & $\begin{array}{c}0,73 \\
(199.2)\end{array}$ & 0.47 & 0.020 \\
\hline 2 & $\begin{array}{l}1500 \\
(0.6)\end{array}$ & $\begin{array}{l}351,4 \\
(0.65)\end{array}$ & 55.2 & 423.3 & 6.35 & 301.1 & $\begin{array}{c}0,74 \\
(220.5)\end{array}$ & 0.88 & 0.030 \\
\hline 3 & $\begin{array}{l}1500 \\
(0.6)\end{array}$ & $\begin{array}{c}527,2 \\
(1.0)\end{array}$ & 82.8 & 473.5 & 6.90 & 180.9 & $\begin{array}{c}0,73 \\
(131.9)\end{array}$ & 1.16 & 0.073 \\
\hline 4 & $\begin{array}{l}1250 \\
(0.4)\end{array}$ & $\begin{array}{l}351,4 \\
(0.65)\end{array}$ & 46.0 & 332.8 & 7.01 & 211.8 & $\begin{array}{c}0,73 \\
(155.1)\end{array}$ & 1.22 & 0.066 \\
\hline 5 & $\begin{array}{l}1750 \\
(0.8)\end{array}$ & $\begin{array}{l}351,4 \\
(0.65)\end{array}$ & 64.4 & 523.8 & 6.38 & 211.3 & $\begin{array}{c}0,73 \\
(154.5)\end{array}$ & 0.61 & 0.030 \\
\hline
\end{tabular}

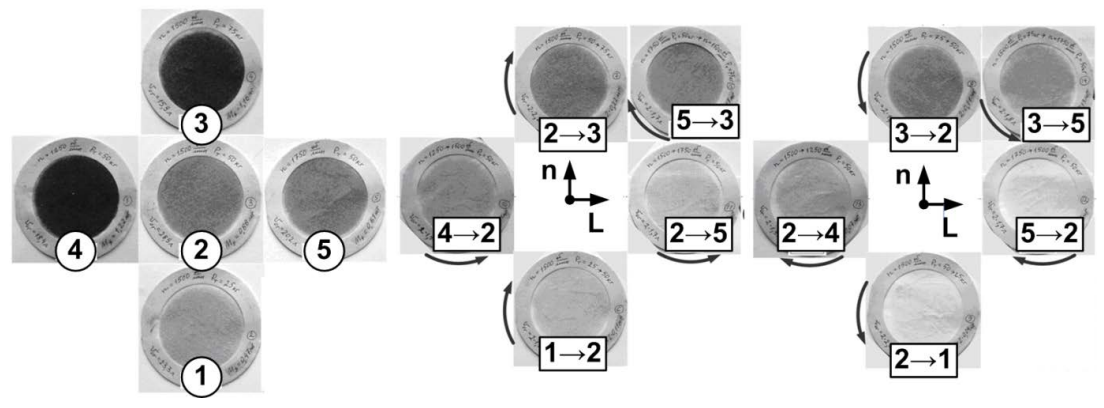

Figure 9. Photos of filters from PM in the course of testing a 4ChN12/14 diesel engine in cycles $A$ and $B$ 
Table 6

The results of determining the coefficients $K_{n}$ and $K_{L}$ dependence (14) during the execution of cycle $B$

\begin{tabular}{|c|c|c|c|c|c|c|c|c|c|c|}
\hline \multirow[b]{2}{*}{ Mode } & \multicolumn{4}{|c|}{$\begin{array}{l}\text { Parameters of unsteady } \\
\text { modes }\end{array}$} & \multicolumn{6}{|c|}{ Results of measurements and calculations } \\
\hline & $\Delta \overline{\mathbf{n}}$ & $\Delta \overline{\mathbf{L}}$ & $\begin{array}{c}\Delta \mathrm{t}= \\
\tau_{\mathrm{sam}}, \mathrm{s}\end{array}$ & $\begin{array}{c}\mathbf{P}_{\mathrm{e}}, \\
\mathbf{k W}\end{array}$ & $\begin{array}{l}\mathrm{G}_{\text {exh }}, \\
\mathrm{kg} / \mathrm{h}\end{array}$ & $\mathbf{q}$ & $\begin{array}{c}\mathbf{c}_{\mathrm{pt}}^{\mathrm{un}}\left(\mathbf{c}_{\mathrm{pt}}^{\mathrm{st}}\right) \\
\mathrm{g} / \mathrm{kg}\end{array}$ & $\begin{array}{c}\Delta \mathrm{c}_{\mathrm{pt}(\mathrm{ex})}, \\
\mathrm{g} / \mathrm{kg}\end{array}$ & $\begin{array}{c}\mathbf{K}_{\mathbf{n}}^{* * *}, \\
(\mathbf{g} \cdot \mathbf{s}) / \\
\mathbf{~ k g}\end{array}$ & $\begin{array}{c}\mathbf{K}_{\mathbf{L}}{ }^{* * *}, \\
\mathbf{( g} \cdot \mathbf{s}) / \\
\mathbf{~ k g}\end{array}$ \\
\hline $1 \rightarrow 2$ & \multirow{2}{*}{0} & \multirow{2}{*}{0.35} & 21.09 & 41.4 & 413.5 & 8.43 & $\begin{array}{c}0.055 \\
(0.025)\end{array}$ & 0.030 & \multirow{2}{*}{ - } & \multirow{2}{*}{1.79} \\
\hline $2 \rightarrow 3$ & & & 22.21 & 69.0 & 448.4 & 6.20 & $\begin{array}{c}0.080 \\
(0.052)\end{array}$ & 0.028 & & \\
\hline $3 \rightarrow 2$ & \multirow{2}{*}{0} & \multirow{2}{*}{-0.35} & 21.07 & 69.0 & 448.4 & 6.65 & $\begin{array}{c}0.057 \\
(0.052)\end{array}$ & 0.005 & \multirow{2}{*}{-} & \multirow{2}{*}{0.00} \\
\hline $2 \rightarrow 1$ & & & 21.27 & 41.4 & 413.5 & 6.43 & $\begin{array}{c}0.020 \\
(0.025)\end{array}$ & -0.005 & & \\
\hline $4 \rightarrow 2$ & \multirow{2}{*}{0.2} & \multirow{2}{*}{0} & 21.30 & 50.6 & 378.1 & 6.82 & $\begin{array}{c}0.058 \\
(0.048)\end{array}$ & 0.010 & \multirow{2}{*}{0.96} & \multirow{2}{*}{ - } \\
\hline $2 \rightarrow 5$ & & & 21.33 & 59.8 & 473.6 & 7.81 & $\begin{array}{c}0.038 \\
(0.030)\end{array}$ & 0.008 & & \\
\hline $5 \rightarrow 2$ & \multirow{2}{*}{-0.2} & \multirow{2}{*}{0} & 20.83 & 59.8 & 473.6 & 7.47 & $\begin{array}{c}0.029 \\
(0.030)\end{array}$ & -0.001 & \multirow{2}{*}{0.26} & \multirow{2}{*}{-} \\
\hline $2 \rightarrow 4$ & & & 21.11 & 50.6 & 378.1 & 9.83 & $\begin{array}{c}0.054 \\
(0.048)\end{array}$ & 0.006 & & \\
\hline $3 \rightarrow 5$ & 0.2 & -0.35 & 20.69 & 73.6 & 498.7 & 7.10 & $\begin{array}{c}0.064 \\
(0.052)\end{array}$ & $\begin{array}{l}0.012 \\
0.009^{*}\end{array}$ & 0.96 & 0 \\
\hline $5 \rightarrow 3$ & -0.2 & 0.35 & 20.11 & 73.6 & 498.7 & 7.48 & $\begin{array}{c}0.079 \\
(0.052)\end{array}$ & $\begin{array}{l}0.027 \\
0.031^{*}\end{array}$ & 0 & 1.79 \\
\hline
\end{tabular}

Notes. * The value of $\Delta \mathrm{c}_{\text {ptex }}$ calculated using the dependence (13); ${ }^{* *}$ presents the arithmetic mean values of the coefficients according to the results of 2 measurements. 


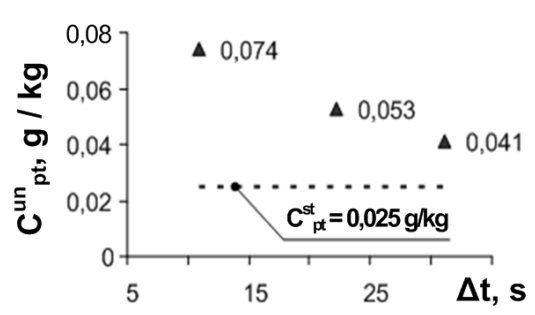

a)

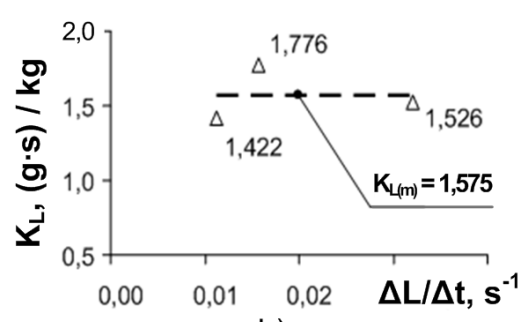

b)

Figure 10. The results of studies of the influence of $\Delta t$ on the PM content in EG during the execution of cycle $C$ :

a) influence on $\Delta c_{p t}$; ) influence on $K_{L}$

An analysis of the results of the execution of cycle B shows the following (see Table 6):

- with the growth of one of the values $\Delta \overline{\mathrm{n}}$ or $\Delta \overline{\mathrm{L}}$ with a constant value of another value, the average values of the coefficients $\mathrm{K}_{\mathrm{n}}$ and $\mathrm{K}_{\mathrm{L}}$ are 0.96 and 1.79 , respectively; while the absolute and relative deviations of the $\mathrm{K}_{\mathrm{n}}$ and $\mathrm{K}_{\mathrm{L}}$ values of the average values are: $\pm 0.08(\mathrm{~g} \cdot \mathrm{s}) / \mathrm{kg}$ or $8.3 \%$ and $\pm 0.06(\mathrm{~g} \cdot \mathrm{s}) / \mathrm{kg}$ or $3.4 \%$, respectively; thus, the load L has a 1.9 -fold more significant effect on $\Delta \mathrm{c}_{\mathrm{pt}}$ than the number of revolutions of the engine crankshaft $\mathrm{n}$;

- when one of the values $\Delta \overline{\mathrm{n}}$ or $\Delta \overline{\mathrm{L}}$ decreases a constant value of another value, the values of the coefficients $\mathrm{K}_{\mathrm{n}}$ and $\mathrm{K}_{\mathrm{L}}$ are not significant and may not be taken into account, since the deviations of the PM concentrations determined in unsteady and steady-state test modes are $\Delta \mathrm{c}_{\mathrm{pt}}=0.005 \ldots 0.006 \mathrm{~g} / \mathrm{kg}$, which is comparable with the limit of sensitivity of MKT- $- \pm 0.005 \mathrm{~g} / \mathrm{kg}$;

- the absolute deviations of the calculated values of $\Delta c_{p t}$ determined using dependence (13) from the experimental data obtained during the execution of 2 control unsteady modes of cycle B are $-0.003 \mathrm{~g} / \mathrm{kg}$ and 0.004 $\mathrm{g} / \mathrm{kg}$, which is comparable with the sensitivity limit MKT-2, this confirms the significance of the obtained values of the coefficients $\mathrm{K}_{\mathrm{n}}$ and $\mathrm{K}_{\mathrm{L}}$ and the practical suitability of dependence (13) for estimating $\Delta \mathrm{c}_{\mathrm{pt}}$.

The results of the execution of cycle $C$ showed the following (see Figure 10):

- with an increase in the duration of the unstable regime $\Delta t$ the differences in the concentrations of PM c ${ }_{p t}^{\text {un }}$ and $c^{\text {st }}$ decrease; so, with an increase in $\Delta \mathrm{t}$ from 10 to $30 \mathrm{~s}$, the $\Delta \mathrm{c}_{\mathrm{pt}}$ value decreases from $0.049 \mathrm{~g} / \mathrm{kg}$ to $0.016 \mathrm{~g} / \mathrm{kg}$, that is, by 3.1 times; 
- in the studied range of variation of $\Delta t$, the coefficient $K_{L}$ can be considered a constant value, the average value of which is 1.575 ; while RSM of this value is $\pm 0.105(\mathrm{~g} \cdot \mathrm{s}) / \mathrm{kg}$ or $\pm 6.7 \%$.

Thus, taking into account the selected type of regression dependence for estimating the $\Delta c_{p t}$ value and the results of experimental studies, the formula for determining the PM concentration in the EG of a diesel engine under unsteady test conditions is:

$$
c_{p t}^{u n}=c_{p t}^{s t}+0,96 \cdot\left(\frac{\Delta \bar{n}_{+}}{\Delta t}\right)+1,575 \cdot\left(\frac{\Delta \bar{L}_{+}}{\Delta t}\right), \mathrm{g} / \mathrm{kg},
$$

where $\Delta \bar{n}_{+}, \Delta \bar{L}_{+}-$the positive values of the velocities of the variable in time $\bar{n}$ and $\bar{L}$.

The practical value of formula (19) lies in the fact that it allows one to estimate the content of PM in EG in unsteady diesel operation modes, which are characterized by an unstable period of $10 \ldots 30 \mathrm{~s}$ and ranges of variation of the parameters $\mathrm{n}, \mathrm{L}, \Delta \mathrm{n} / \Delta \mathrm{t}$ and $\Delta \mathrm{L} / \Delta \mathrm{t}$ reduced to a dimensionless form $0.4 \ldots 0.8,0.3 \ldots 1.0,-0.2 \ldots 0.2$ and $-0.35 \ldots 0.35$, respectively with errors that are comparable with the errors of the gravimetric measurement system - microtunnels MKT-2.

\section{Optical-gravimetric method of indirect control of PM content in EG}

Requirements for the accuracy of modern PM control methods. Gradual reduction in the permissible levels of PM emissions from diesel engines leads to an increase of the resulting error in measurement of the standardized ecological index - an average operating emission of particulate matter PM from EG. Thus, shifting from standard Euro 1 to Euro 6 standards of the specified index for automotive diesel decreased by 72 times from 0.36 to $0.005 \mathrm{~g} / \mathrm{kWh}$, and the resulting uncertainty of its determination accordingly increased: from 3 to $22 \%$ (7.3 times) - when conducting research in the same lab; from 12 to $57 \%$ (4.8 times) - when research has been conducted in different laboratories (Figure 11) [15].

In order to ensure the required accuracy of determining the mass PM emissions, which are in the range of $0.005 \ldots 0.02 \mathrm{~g} / \mathrm{kWh}$, the modern measurement methods of concentrations PM shall have a sensitivity 2-5 $\mathrm{mcg} / \mathrm{m}^{3}$ [16]. The best known high-precision inspection techniques for PM emissions include: tapered element oscillating microbalance (TEOM) based on compliance with resonant frequency of a trap, which 


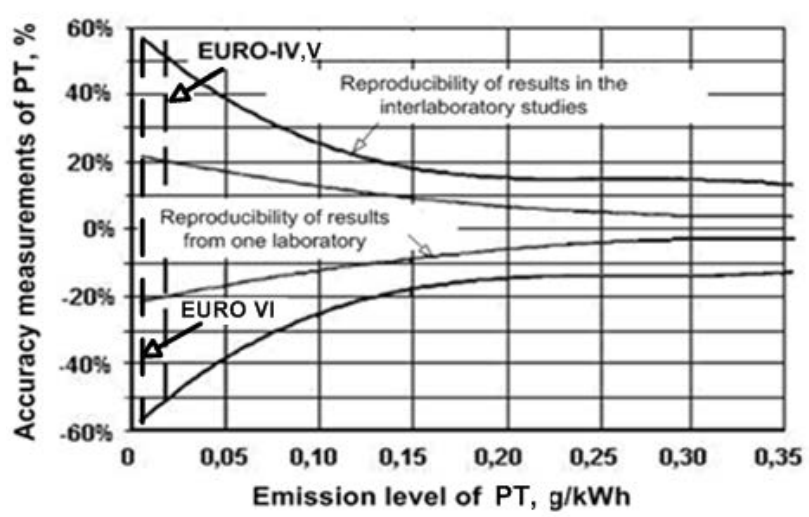

Figure 11. Measurement error increase in determining the average operating emission of $P M$ in the conditions of reduction of emission standards for diesel engines EG

is used to collect the particles with a mass of material that is captured [17]; microbalance with piezoelectric sensing element - quartz crystal, on the faces of which the PM are deposited (Quartz Crystal Microbalance QCM) [18]; the PT quantitative analysis method using laser-induced EG incandescence (Laser Induced Incandescence - LII), which allows simultaneous measuring of PM mass and number concentration, as well as the sizes of the primary soot particulates - by means of a single instrument [19] and others.

Work on the creation of domestic analogues of modern high-precision methods and equipment for measuring PM emissions from transport and industrial diesel engines is of high relevance. The authors have proposed and investigated an indirect optical-gravimetric method for monitoring PM concentrations and emissions in steady-state diesel operation modes.

The essence of the optical gravimetric PM control method is to use the PM capabilities contained in diesel EG to absorb light radiation passing through a stream of a representative gas sample; thus changing the optical density of the sample flow, which has a correlation with the PM concentration [20].

The operating principle of this method is as follows (Figure 12). 
Before analyzing diesel EG, in order to simulate the natural process of their getting into the atmosphere, they are previously diluted with clean air to a temperature not exceeding $52^{\circ} \mathrm{C}$, in the sample preparation and calibration system of the PM concentrations optical detector, which is microtunnel MKT-2 (see Figure 3). In a special module (Figure 13), prepared gas sample is divided into two streams with equal mass flow rates, one of which is directed to the reference channel and another - to the working path (channel) of the PM concentration meter. Each of these channels has an electric particulate filter for trapping diesel PM (Figure 14), the filter in comparative channel is being constantly used in the course of taking measurements and the filter in working path being used only when setting zero at the PM concentration detector.

From the two channels, the flows of gas samples (one of which contains the PM) enter the optical PM detector (Figure 15), wherein the corresponding optical densities of flows are determined, and the difference between them being a function from the PM concentration in the diesel EG. Setting this function is performed by calibrating optical PM detector in accordance with the procedure set out below.

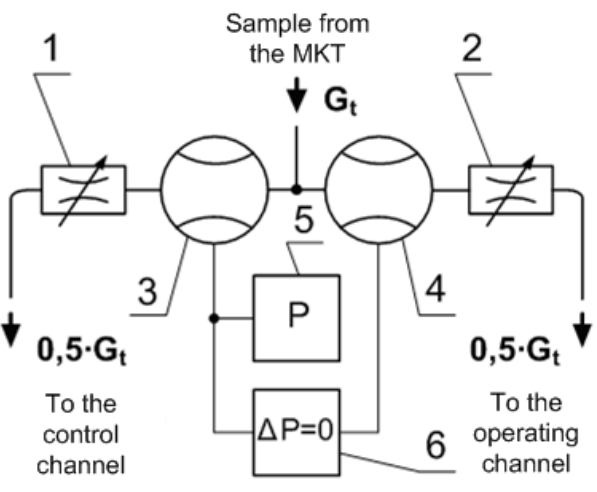

Figure 13. Schematic diagram of the sample flow rate distribution module: 1,2 - sample flow control devices; 3,4 - flowmeters; 5, 6-differential pressure transmitters 


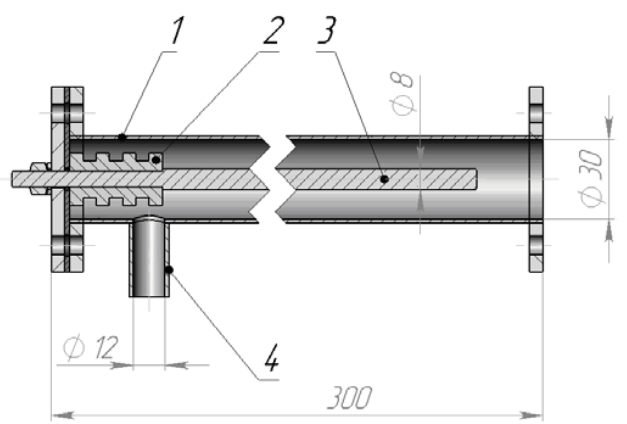

Figure 14. Electric filter for PM catching:

1 - pipeline; 2 - insulator; 3 - metal rod; 4 - connecting pipe

Sample from the control channel

Sample from the operating channel

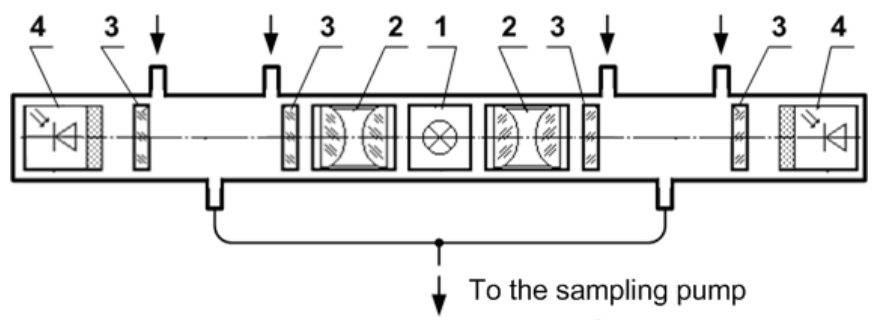

Figure 15. Schematic diagram of the optical PM detector:

1 - light source assembly; 2 - a system of optical lenses;

3 - protective glasses; 4 - light detector with a compensating filter

To implement the described method, a prototype PM meter has been developed, which allows to control the instantaneous values of PM concentrations and emissions: $\mathrm{c}_{\mathrm{pt}}, \mathrm{PT}_{\text {mass }}$ and $\mathrm{PT}_{\mathrm{p}}$.

The method for determining the quantitative characteristics of the PM content in EG of diesel engines provides for the following algorithm:

1. During tests of a diesel engine on the brake tester equipped with PM meter, the instantaneous values of the following parameters are determined:

- the number of revolutions of the engine crankshaft $-\mathrm{n}\left(\mathrm{min}^{-1}\right)$ and torque on engine shaft $-\mathrm{M}_{\mathrm{k}}(\mathrm{N} \cdot \mathrm{m})$;

- load on the motor shaft $-\mathrm{L}$, which is determined by the formula 


$$
L=\frac{\mathrm{M}_{k}}{\mathrm{M}_{k(\max )}} \cdot 100 \%
$$

where $\mathrm{M}_{\mathrm{k}(\max )} \cdot$ - maximum torque on the motor shaft at the current value n; - diesel EG mass flow rate in the exhaust pipe $-\mathrm{G}_{\text {exh }}(\mathrm{kg} / \mathrm{h})$;

- optical densities of the diluted EG sample streams flowing in the working $-\mathrm{N}_{1}(\%)$ and the control $-\mathrm{N}_{0}(\%)$ channels of the optical PM detector.

2. Instantaneous values of $\mathrm{n}$ and $\mathrm{L}$ determine the mass concentration of $\mathrm{PM}$ in diesel EG in the corresponding steady-state operation of the engine:

$$
c_{p t}=K_{\bmod e}(n, L) \cdot \operatorname{Ln}\left(1-\frac{N_{1}-N_{0}}{100}\right), \mathrm{g} / \mathrm{kg},
$$

where $\mathrm{K}_{\text {mode }}(\mathrm{n}, \mathrm{L})$ - proportionality factor that depends on the test mode and it is determined during the calibration of the optical PM detector.

To determine the value of $\mathrm{C}_{\mathrm{pt}}^{\mathrm{st}}$, a type of dependence is chosen based on the MIRA (The Motor Industry Research Association) recommendations by the indirect determination of PM concentrations using the index of EG smokiness [20].

4. The values of the mass and specific emissions of PM from the EG of a diesel engine are determined using dependencies (3) and (4)

The calibration procedure of the PM optical detector involves establishing a dependence for determining the coefficient $\mathrm{K}_{\text {mode }}(\mathrm{n}, \mathrm{L})$, which is used in formula (21) for indirect measurement of the value of $\mathrm{c}_{\mathrm{pt}}$. This procedure is a 2-factor experiment, which consists of 4 basic and 3 control measurements; according to its results, the 1st order regression equation with normalized variables is determined (Figure 16):

$$
K_{\text {mode }}=a_{0}+a_{1} \cdot X_{1}+a_{2} \cdot X_{2}
$$

where $\mathrm{a}_{0}, \mathrm{a}_{1} \mathrm{i} \mathrm{a}_{2}$ - constant coefficients,

$$
X_{1}=\frac{\bar{n}-\bar{n}_{\text {mid }}}{\bar{n}_{\text {step }}} ; X_{2}=\frac{\bar{L}-\bar{L}_{\text {mid }}}{\bar{L}_{\text {step }}}-\text { normalized variables, }
$$

$\bar{n}_{\text {mid }}=0,8, \bar{L}_{\text {mid }}=0,75$ - average values of $\bar{n}$ and $\bar{L}$ magnitude variation range;

$\bar{n}_{\text {step }}=0,2 ; \bar{L}_{\text {step }}=0,25-$ steps of changing the values $\bar{n}$ and $\bar{L}$;

The coefficients of the regression dependence (22) are determined by the results of the basic tests as follows [21]:

$$
a_{0}=\frac{1}{4} \cdot \sum_{i=1}^{4} K_{\bmod e_{i}}
$$




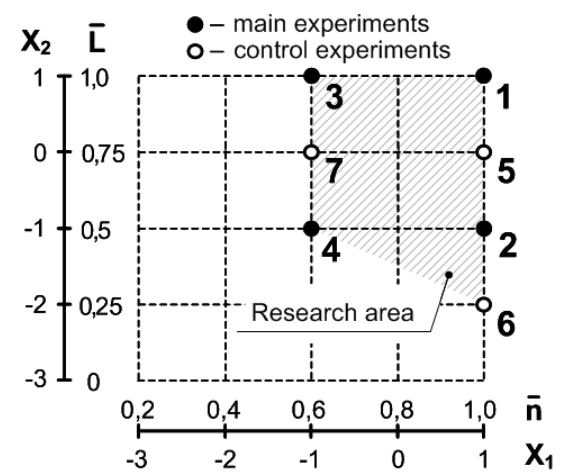

Figure 16. Plan of the two-factor experiment to determine the dependence of $K_{\text {mode }}(n, L)$ in the scope of study:

$$
\begin{gathered}
\bar{n}=\mathbf{0 , 6} \ldots \mathbf{1 , 0}, \frac{\mathrm{L}}{=}=\mathbf{0 , 2 5} \ldots \mathbf{1 , 0} \\
a_{1}=\frac{1}{4} \cdot\left(K_{\bmod e 1}+K_{\bmod e 2}-K_{\bmod e 3}-K_{\bmod e 4}\right) ; \\
a_{2}=\frac{1}{4} \cdot\left(K_{\bmod e 1}-K_{\bmod e 2}+K_{\bmod e 3}-K_{\bmod e 4}\right),
\end{gathered}
$$

where $\mathrm{i}=1 \ldots 4$ - an index of the basic test;

$\mathrm{K}_{\text {modei }}$ - experimentally determined value of the coefficient $\mathrm{K}_{\text {mode }}$ in the i-th test:

$$
K_{\bmod e_{i}}=\frac{c_{p t_{i}}^{\exp }}{\operatorname{Ln}\left(1-\Delta N_{i} / 100\right)^{-1}},
$$

where $\mathrm{c}^{\exp }$ pti $-\mathrm{PM}$ concentration, which is measured using MKT-2 in the i-th test, $\mathrm{g} / \mathrm{kg}$;

$\Delta \mathrm{N}_{\mathrm{i}}$ - the difference of the optical densities of the sample flows in the working and control channels of the optical PT detector in the i-th test, $\%$.

Calibration results of the PM optical detector. On the basis of the experimental setup described above for the study of PM content in EG in accordance with the presented test procedure, a 2-factor experiment has been conducted. The results are shown in Table 7 .

Based on the results of basic tests 1-4 using formulas (23) - (25), the coefficients of the regression dependence - polynomial of the 1st order are determined (22): $\mathrm{a}_{0}=0.334, \mathrm{a}_{1}=-0,017, \mathrm{a}_{2}=-0.068$. 
Andrey Polivyanchuk, Igor Gritsuk, Elena Skuridina

\begin{tabular}{|c|c|c|c|c|c|c|c|c|c|}
\hline \multirow{12}{*}{ 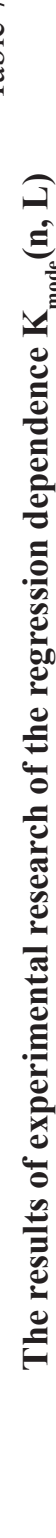 } & \multirow{6}{*}{ 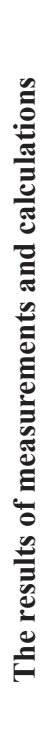 } & 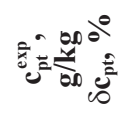 & 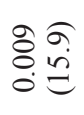 & 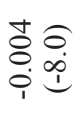 & 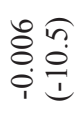 & $\begin{array}{l}\overrightarrow{8} \hat{\sigma} \\
0 \cdot \dot{0}\end{array}$ & 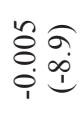 & $\begin{array}{l}\hat{8} \underset{0}{0} \\
\dot{0} \dot{0}\end{array}$ & $\begin{array}{l}n \\
8 \\
0 \\
0 \\
0 \\
0\end{array}$ \\
\hline & & 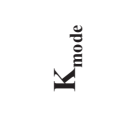 & $\frac{n}{n}$ & $\frac{n}{\frac{n}{7}}$ & $\frac{\pi}{n}$ & $\begin{array}{l}n \\
n \\
\infty \\
\vdots \\
0\end{array}$ & $\frac{\underbrace{0}_{0}}{0}$ & $\begin{array}{l}\stackrel{0}{0} \\
\text { ஸे } \\
\stackrel{0}{0}\end{array}$ & 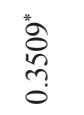 \\
\hline & & 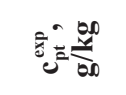 & $\begin{array}{l}\infty \\
\stackrel{0}{0} \\
0\end{array}$ & $\begin{array}{l}\text { J } \\
\text { Oे }\end{array}$ & 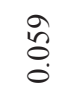 & $\begin{array}{l}\bar{\checkmark} \\
0 \\
0\end{array}$ & $\begin{array}{l}n \\
\tilde{c} \\
0\end{array}$ & $\begin{array}{l}\hat{\infty} \\
0 \\
0\end{array}$ & 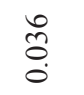 \\
\hline & & $\bar{z} \theta^{0}$ & $\begin{array}{l}n \\
\text { ñ }\end{array}$ & กี & $\frac{9}{9}$ & 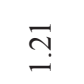 & 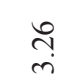 & $\stackrel{\circ}{+}$ & $\bar{a}$ \\
\hline & & $\sigma$ & શे & $\hat{a}$ & $\underset{f}{\stackrel{f}{+}}$ & $\underset{\sim}{\stackrel{\infty}{\sim}}$ & $\underset{g}{\stackrel{g}{+}}$ & $\stackrel{\overbrace{}}{\forall}$ & $\begin{array}{l}\text { 寸 } \\
\dot{\forall}\end{array}$ \\
\hline & & 产 & $\stackrel{0}{i}$ & $\stackrel{i}{i}$ & $\stackrel{n}{\infty}$ & 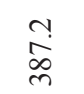 & ลิ & $\begin{array}{l}\vec{\infty} \\
\infty \\
+\end{array}$ & ஸे \\
\hline & \multirow{5}{*}{ 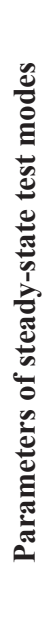 } & 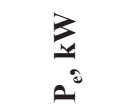 & $\ddot{\circ}$ & $\stackrel{\circ}{\circ}$ & $\begin{array}{l}0 \\
\infty \\
\infty\end{array}$ & $\ddot{\vartheta}$ & $\stackrel{\varphi}{r}$ & $\begin{array}{l}0 \\
i j\end{array}$ & $\begin{array}{l}0 \\
\dot{J}\end{array}$ \\
\hline & & $x^{2}$ & - & $T$ & - & $T$ & 0 & $\Upsilon$ & 0 \\
\hline & & 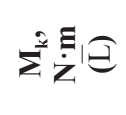 & 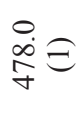 & 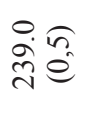 & 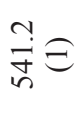 & 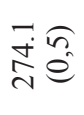 & $\bar{n} \frac{n}{2}$ & 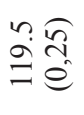 & กิ \\
\hline & & $\bar{x}$ & - & 一 & $T$ & $T$ & - & - & $T$ \\
\hline & & 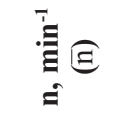 & 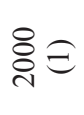 & $\stackrel{\overbrace{}}{\overbrace{}} \bigodot$ & $\begin{array}{l}80 \\
\because 0\end{array}$ & 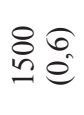 & $\stackrel{\overbrace{}}{\overbrace{}}$ & $\underset{\overbrace{}}{\overbrace{}} \rightleftharpoons$ & 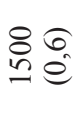 \\
\hline & & 苍 & - & $\sim$ & $n$ & $\nabla$ & $n$ & 0 & $r$ \\
\hline
\end{tabular}


Thus, for determining the concentration of PM in EG on steady-state modes of the diesel engine, the dependence is as follows:

- with normalized variables $\mathrm{X}_{1}$ and $\mathrm{X}_{2}$ :

$$
c_{p t}^{s t}=\left(0.334-0,017 \cdot X_{1}-0.068 \cdot X_{2}\right) \cdot \operatorname{Ln}(1-\Delta \mathrm{N} / 100)^{-1} ;
$$

- with dimensionless variables $\bar{n}$ and $\bar{L}$ :

$$
c_{p t}^{s t}=(0.606-0.085 \cdot \bar{n}-0.272 \cdot \bar{L}) \cdot \operatorname{Ln}(1-\Delta \mathrm{N} / 100)^{-1}
$$

Based on the results of control experiments 5-7, the absolute $\Delta c_{p t}$, the relative $\delta \mathrm{c}_{\mathrm{pt}}$ and the standard deviations of the calculated values of $\mathrm{c}_{\mathrm{pt}}$ (obtained using dependence (28)) from the experimental data $-\mathrm{S}_{\mathrm{cpp}}$, have been determined. The calculation results $-\Delta \mathrm{c}_{\mathrm{pt}}=-0.005 . .0 .007 \mathrm{~g} / \mathrm{kg}, \delta \mathrm{c}_{\mathrm{pt}}=-9 \ldots 13 \%, \mathrm{~S}_{\mathrm{cpt}}= \pm 0.006 \mathrm{~g} / \mathrm{kg}$ are comparable with the accuracy characteristics of microtunnels MKT-2.

Thus, the results of the experiment have shown satisfactory accuracy and practical suitability of the optical-gravimetric method proposed by the authors for indirect control of the PM content in EG diesel engine under steady-state modes in the ranges of parameters $\bar{n}$ and $\bar{L}: 0.6 \ldots 1.0$ and $0.25 \ldots 1.0$, respectively.

\section{Conclusions}

1. On the basis of the motor stand of a $4 \mathrm{ChN} 12 / 14$ autotractor diesel equipped with a partial-flow system of dilution of EG with air - microtunnels MKT-2, mathematical modeling of the influence of engine operating conditions on the content in the exhaust gas of hazardous pollutant - PM has been carried out. There has been researched the influence of the parameters of steady-state modes - the number of revolutions of the crankshaft $-n$ and the load $-\mathrm{L}$ and the parameters of unstable modes - the values of $\mathrm{n}$, $\mathrm{L}$ and the rates of their change in time $-\Delta \mathrm{n} / \Delta \mathrm{t}$ and $\Delta \mathrm{L} / \Delta \mathrm{t}$ on the mass and volume concentrations $-\mathrm{c}_{\mathrm{pt}}$ and $\mathrm{C}_{\mathrm{pt}}$ mass $-\mathrm{PT}_{\text {mass }}$ and specific $-\mathrm{PT}_{\mathrm{p}}$ emissions PM. Control PM emissions have been by the gravimetric method in accordance with the requirements of regulatory documents - ISO8178 standard, UNECE Rules R-49, R-96, etc. with errors of $\pm 3 \ldots 10 \%$. Established during the research, the mathematical models form the basis of an economical and easy-to-use calculation method for controlling the PM content in the EG at constant and unstable diesel operation modes.

2. As a result of studies of concentrations and emissions PM at steadystate diesel operation modes, the type has been selected and the coefficients 
of the most reliable regression dependence have been determined - a second-order polynomial model, which allows us to estimate the values of $\mathrm{C}_{\mathrm{pt}}$, $\mathrm{PT}_{\text {mass }}$ and $\mathrm{PT}_{\mathrm{p}}$ in the ranges of variation of the parameters $\mathrm{n}$ and $\mathrm{L}-1000 \ldots$ $2000 \mathrm{~min}^{-1}$ and $25 \ldots 100 \%$. The RSM of the established dependencies when determining the indicated values is comparable with the errors of microtunnels MKT-2 and is $\pm 0.0042 \mathrm{~g} / \mathrm{mn}^{3}, \pm 2.02 \mathrm{~g} / \mathrm{h}, \pm 0.077 \mathrm{~g} /(\mathrm{kWh})$.

3. A dependence has been established for indirectly determining the mass concentrations of PM in the EG at unsteady diesel operating modes, which are characterized by a duration of $10 \ldots 30 \mathrm{~s}$ and ranges of variation of the parameters $\mathrm{n}, \mathrm{L}, \Delta \mathrm{n} / \Delta \mathrm{t}$ and $\Delta \mathrm{L} / \Delta \mathrm{t}$, given in dimensionless form: $0.4 \ldots 0.8,0.3 \ldots 1.0,-0.2 \ldots 0.2$ and $-0.35 \ldots 0.35$, respectively. The deviation of the calculated and experimental data when using this dependence is \pm $0.005 \ldots 0.006 \mathrm{~g} / \mathrm{kg}$, which is comparable with the sensitivity limit of MKT-2.

4. An indirect optical gravimetric method for controlling PM concentrations and emissions at steady-state diesel engine operating modes has been proposed and studied. This method provides for the establishment and use of a regression dependence for determining the mass concentration of $\mathrm{PM}-\mathrm{c}_{\mathrm{pt}}$ by the optical opacity (smoke) EG diesel engine. A satisfactory accuracy comparable with the accuracy of MKT-2 microtunnels and the practical suitability of the proposed method for controlling the PM content in EG with varying parameters and in the ranges of $1000 \ldots 2000 \mathrm{~min}^{-1}$ and $25 \ldots 100 \%$, respectively, are experimentally confirmed. The absolute and relative errors in determining the value of $\mathrm{c}_{\mathrm{pt}}$ using this method have been $-0.005 . .0 .007 \mathrm{~g} / \mathrm{kg}$ or $-9 \ldots 13 \%$, respectively.

\section{References:}

1. Zvonov, V. A. (2004). Ekologiya avtomobil'nykh dvigateley vnutrennego sgoraniya [Ecology of automobile internal combustion engines]. Lugansk: VNU named after V. Dahl, 268 p. (in Russian)

2. Bielaczyc, P., \& Woodburn Szczotka, J. (2016). Exhaust Emissions of Gaseous and Solid Pollutants Measured over the NEDC, FTP-75 and WLTC Chassis Dynamometer Driving Cycles. SAE Technical Paper, 2016-01-1008, 13 .

3. Foote, E., Maricq, M., Sherman, M., Carpenter, D. et al. (2013). Evaluation of Partial Flow Dilution Methodology for Light Duty Particulate Mass Measurement. SAE Technical Pape, 2013-01-1567, 10.

4. Littera, D., Cozzolini, A., Besch M., Velardi, M. et al. (2013). Comparison of Particulate Matter Emissions from Different Aftertreatment Technologies in a Wind Tunnel. SAE Technical Paper, 2013-24-0175, 17.

5. Alkidas, A. C. (1984). Relationship Between Smoke Measure-ments and Particulate Measurements. SAE Technical Paper. 840412, 316-322. 
6. Kuharenok, G. M. (2016). Otsenka soderzhaniya dispersnykh chastits v otrabotavshikh gazakh dizel'nykh dvigateley [Estimation of the content of dispersed particles in the exhaust gases of diesel engines]. Science and technology, vol. 15, no. 5, pp. 371-379. (in Russian)

7. Kittelson, D., \& Kraft, M. (2015). Particle Formation and Models. Encyclopedia of Automotive Engineering, no. 1(23), pp. 107-130.

8. Muntean, G. G. (1999). A Theoretical Model for the Correlation of Smoke Number to Dry Particulate Concentration in Diesel Exhaust. SAE Technical Paper. 1999-01-0515, 316-322.

9. Polivyanchuk, A., Kaslin, O., \& Skuridina, E. (2018). Effectiveness evaluation of the measuring system with a microtunnel MKT-2 for ecological diagnosis of diesel locomotives. Internal combustion engines, no. 2, pp. 72-76.

10. Schenk, H. (1972). Teoriya inzhenernogo eksperimenta [Theory of Engineering Experiment]. Moscow: «Peace», 382 p. (in Russian)

11. Novitsky, P., \& Zograph, I. (1985). Otsenka pogreshnostey rezul'tatov izmereniy [Estimation of errors of measurement results]. St.-P.: Energoatomizdat, 248 p. (in Russian)

12. Zazhigaev, L. S., Kishyan, A. A., \& Romanikov, Y. I. (1978). Metody planirovaniya i obrabotki rezul'tatov fizicheskogo eksperimenta [Methods of planning and processing the results of a physical experiment]. Moscow: Atomizdat, $232 \mathrm{p}$.

13. Polyvyanchuk, A. P. (2019). Ocinka ekonomichnoji efektyvnosti sposobu pryskorenogho vymiru vykydiv tverdykh chastynok $\mathrm{z}$ vidpracjovanymy ghazamy teplovoziv [Evaluation of economic efficiency of the method of accelerated measurement of particulate emissions from exhaust gases of diesel locomotives]. Municipal utilities. Series: Economic Sciences, no. 4(150), pp. 35-39. (in Ukrainian)

14. Afanasyev, V. A. (2017). Probability Theory: Student for Universities. Moscow: Vlados, 352 p. (in Russian)

15. Burtscher, H. (2001). Literature Study on Tailpipe Particulate Emission Measurement for Diesel Engines. Done for the Particle Measurement Programme (PMP) for BUWAL/GRPE. Fachhochschule Aargau, University of Applied Science, Windisch, Switzerland, $45 \mathrm{p}$.

16. Anderson, J. D. (2003). UK Particle Measurement Programme. Phase 2. Heavy Duty Methodology Development. Final Report. Ricardo Consulting Engineers Ltd, 222 p.

17. Seito, K., \& Shinozaki, O. (1990). The measurement of diesel particulate emissions with tapered element oscillating microbalance and an opacimeter. SAE Technical Paper. 900644, 1-5.

18. Abe, T., Sato, T., \& Hayashida, M. (1989). Particulate matter emission characteristics under transient pattern driving. SAE Technical Paper. 890468, 151-163.

19. Schraml, S., Will, S., \& Leipertz, A. (1999). Simultaneous measurement of soot mass concentration and primary particle size in the exhaust of DI diesel engine by time-resolved laser-induced incandescence (TIRE-LII). SAE Technical Paper, 1999-01-0146, 8.

20. Hardenberg, H., \& Albreht, H. (1987). Grenzen der Rubmassnbestimmung aus optishen Transmessungen. MTZ: Motortechn, no. 48, vol. 2, pp. 51-54.

21. Adler, Y. P., Markova, E. V., \& Granovsky, Y. V. (1976). Planirovanie jeksperimenta pri poiske optimal'nyh uslovij [Planning an experiment when searching for optimal channels]. Moscow: «Science», 280 p. (in Russian) 